\title{
Article \\ Cost-Aware Design and Fabrication of New Support Structures in Laser Powder Bed Fusion: Microstructure and Metallurgical Properties
}

\author{
Bharath Bhushan Ravichander ${ }^{1}$, Sourabh Thakare ${ }^{1}$, Aditya Ganesh-Ram ${ }^{1}$, Behzad Farhang ${ }^{1}$, \\ Manjunath Hanumantha ${ }^{1}$, Yiran Yang ${ }^{2}$, Narges Shayesteh Moghaddam ${ }^{1}$ and Amirhesam Amerinatanzi ${ }^{1,3, * \mathbb{D}}$
}

check for updates

Citation: Ravichander, B.B.; Thakare, S.; Ganesh-Ram, A.; Farhang, B.; Hanumantha, M.; Yang, Y.; Shayesteh Moghaddam, N.; Amerinatanzi, A. Cost-Aware Design and Fabrication of New Support Structures in Laser Powder Bed Fusion: Microstructure and Metallurgical Properties. Appl. Sci. 2021, 11, 10127. https:// doi.org/10.3390/app112110127

Academic Editors: Georgios

E Stavroulakis, Loucas Papadakis and Ioannis Ntintakis

Received: 10 September 2021

Accepted: 8 October 2021

Published: 28 October 2021

Publisher's Note: MDPI stays neutra with regard to jurisdictional claims in published maps and institutional affiliations.

Copyright: (c) 2021 by the authors. Licensee MDPI, Basel, Switzerland. This article is an open access article distributed under the terms and conditions of the Creative Commons Attribution (CC BY) license (https:/ / creativecommons.org/licenses/by/ $4.0 /)$.
1 Mechanical and Aerospace Engineering, University of Texas at Arlington, Arlington, TX 76019, USA; bharathbhushan.ravichander@mavs.uta.edu (B.B.R.); sourabhhemant.thakare@mavs.uta.edu (S.T.); adityakrishna.ganeshram@mavs.uta.edu (A.G.-R.); behzad.farhang@mavs.uta.edu (B.F.); manjunath.hanumantha@mavs.uta.edu (M.H.); narges.shayesteh@uta.edu (N.S.M.)

2 Industrial, Manufacturing, and Systems Engineering, University of Texas at Arlington, Arlington, TX 76019, USA; yiran.yang@uta.edu

3 Materials Science and Engineering, University of Texas at Arlington, Arlington, TX 76019, USA

* Correspondence: amir.ameri@uta.edu; Tel.: +1-(817)-272-1286

Abstract: This study investigates the effect of support structures on the properties of Inconel 718 (i.e., IN718) parts produced by the laser powder bed fusion (LPBF) additive manufacturing process. Specifically, the effects of support structure shape (i.e., pin-type, angled-type, cone-type) and geometry (i.e., support wall thickness, and gap) on their composition, hardness, microstructure, and material/time consumption are investigated and compared to the conventionally fabricated Inconel 718. From the microstructural analysis, the deepest melt pools appeared to be formed in the sample fabricated on top of the pin-type support structure having a relatively low wall thickness. The XRD results conveyed that a proper selection of geometrical variables for designing support structure results in elevated levels of the strengthening phases of IN718. The sample fabricated on top of the pin-type support structure showed the highest Vickers hardness value of $460.5 \mathrm{HV}$, which was even higher than what was reported for the heat-treated wrought Inconel 718 (355-385 HV). Moreover, for the thinner support wall thickness, an improvement in the hardness value of the fabricated samples was observed. This study urges a reconsideration of the common approach of selecting supports for additive manufacturing of samples when a higher quality of the as-fabricated parts is desired.

Keywords: laser powder bed fusion; Inconel 718; support structure

\section{Introduction}

The need for a stable, solution-strengthened, and non-hardenable alloy that can also operate at high temperatures $\left(650\right.$ to $\left.760^{\circ} \mathrm{C}\right)$ has led to the development of nickel-based superalloy Inconel 718 (i.e., IN718) [1,2]. IN718 offers exceptionally high mechanical strength even at elevated temperatures (around $700{ }^{\circ} \mathrm{C}$ ) [3], superior thermal resistance [4], and high resistance to corrosion and oxidation [5]. These beneficial features have made IN718 a great candidate in the sector of aircraft engines, turbine blades, combustion chambers, and nuclear reactors [6-8]. One major challenge associated with fabricating IN718, however, is the low machinability arising from its high hardness value (372 HV for wrought IN718 based on AMS 5663 and 350 HV for cast IN718 based on AMS 5383) and low thermal conductivity $\left(11.2 \mathrm{~W} \cdot \mathrm{m}^{-1} \cdot \mathrm{K}^{-1}\right)$ [9], which, in turn, leads to extreme tool wear and unsatisfactory workpiece surface integrity $[10,11]$. In recent years, additive manufacturing technology has attracted great attention for the fabrication of IN718 since it minimizes the need for machining [12]. Amongst all available AM techniques, laser powder bed fusion (LPBF) has widely been adopted within the industry due to the overall cost and fabrication advantages [3,13-15]. 
During the past decade, significant work has been carried out in the context of improving the microstructure and mechanical properties of LPBF-fabricated IN718 through the change in LPBF process parameters [16-18]. In an initial attempt to increase the density and oxygen resistance of fabricated main parts, Jia et al. [19] investigated the effect of laser power $(P)$ and scanning speed $(v)$ on LPBF IN718. Their study revealed that both the oxidation resistance and density of the parts were improved with an increase in the $P / v$ ratio. In terms of the surface analysis, the role of laser processing parameters was found to be significant, too. Valdez et al. [16] reported the formation of discontinuity on the finished surface as well as the balling effect at a low laser energy power $(P)$. On the other hand, at a relatively high value of the laser power $(P)$, Parimi et al. [20] observed increased numbers of entrapped bubbles within the melt pools, thus a decreased level of density. Ravichander et al. [21] conducted a comprehensive study on the effect of laser processing parameters on the geometry accuracy of the as-fabricated sample. Out of all other energy density parameters (laser power $(P)$, hatch spacing $(h)$, and layer thickness $(t)$ ), they found laser scan speed $(v)$ as a dominant factor towards grain length, which affects the final dimension of the part. Conducting microstructural analysis and mechanical testing on as-fabricated parts, Chlebus et al. [22] demonstrated the possibility of manufacturing IN718 parts with $99.8 \%$ density by double scanning strategy. However, the hardness value of their as-fabricated LPBF samples (maximum $322 \mathrm{HV}$ ) did not satisfy the minimum requirement for industrial applications ( $\sim 355-385 \mathrm{HV}$ [2]). Many research groups tried to enhance the microhardness value of the as-fabricated LBPF IN718 samples [14,19,23-36]. So far, Jia et al. [19] reported the highest achieved hardness value of as-fabricated LPBF IN718 samples in the literature as $395.8 \mathrm{HV}$, which was slightly above the minimum requirement per AMS5663. This encouraged more research to be conducted on post-process heat treatment of IN718 samples to push the microhardness to higher values.

Popovich et al. [37] reported the highest achieved hardness value of $478 \mathrm{HV}$ for a post processed LPBF IN718 sample. The post process included hot isostatic pressing at $1180{ }^{\circ} \mathrm{C}$ under $21755.7 \mathrm{psi}$ for $3 \mathrm{~h}$ and heat treated at $650^{\circ} \mathrm{C}$ for $8 \mathrm{~h}$. The heat-treated samples show clear distinct borders between microstructures of fine- and coarse-grained regions along with an increase in carbide density contributing to the hardness improvement. While the study proved that the achieved properties of IN718 are promising, post-process treatments are not ideal as they add to the overall time and cost of creating parts [38].

Support structures also play a significant role in the microstructure, composition, as well as the mechanical properties of LPBF-fabricated IN718. Jiang et al. [39] reviewed a total of 57 publications over the state-of-the-art research in the AM support structure area, but only found eight works [40-47] on the topic of support structure in metal LPBF. Low accessibility to metal 3D printers compared to polymer-based printers and higher expenses could be counted as the main reasons for such limited work on this topic. According to the literature, the role of adding support structures in LPBF falls into three different categories, which include cooling the part through heat conduction, reducing the risk of warpage during fabrication, and manufacturing cost reduction. They have been appropriately discussed by the articles in the literature as follows: (1) conducting the heat away from the part: the support structure can change the pattern of energy conduction from the molten pool to the building plate which can provide a stable thermal condition and thereby reduce the residual stresses within the sample [48]. For LPBF-fabricated parts, this effect has been investigated for the "overhang" state. Kajima et al. [49] studied the fatigue strengths of 45-degree overhanging arms additively manufactured with and without supports using Co-Cr-Mo powder. They observed that the fatigue strength was more than twice for the supported samples because of finer grains found in the microstructure as well as less defects and microcracks in the fracture surfaces of the supported samples. Moreover, lower residual strain was observed for the supported samples compared to unsupported ones. Chen et al. [50] performed thermal simulations on overhanging features when supported with powder versus a solid layer underneath. They reported that printing a part above a solid material would result in a lesser thermal gradient within the part, thus reducing the 
resultant residual stress. They attributed this observation to the lower thermal conductivity of the AlSi10Mg powder, which was about $8 \mathrm{~W} / \mathrm{mK}$ compared to that of around $90 \mathrm{~W} / \mathrm{mK}$ for a solid phase of AlSi10Mg. However, the study was specific to a particular overhang design and did not consider microstructure variations at areas of the overhang supported by powder and that of as-fabricated parts. Moreover, post-processing operations can be time-consuming and more complex as the solid material should be removed from the main part. Therefore, minimizing the volume of the support structure plays an important role in the improvement of the efficiency of the fabrication process; (2) Preventing in-process failure: optimum support structures can reduce or even eliminate warping and distortion in LPBF-fabricated parts. Liu et al. [51] observed a reduced level of warping with a higher concentration of supports near the edges, where laser scanning starts and ends. According to Kruth et al. [52], however, the higher concentration of supports is associated with longer build time, along with difficulty in support removal, which might require further consideration. In a study conducted by Pinto et al. [53], it was revealed that a relatively low support concentration may lead to in-process failure due to the higher chance of particle clustering formation in the initial layers of the part, which they attribute to the increased magnetic interactions between particles. They also reported the same phenomenon for the reused powder materials and ferrite materials such as 316 L.SsteelPal et al. [54] attributed the formation of such defects to several physical actions as well as thermodynamic effects in the molten pool induced by laser and support structures. They suggested optimization of laser processing parameters, mainly the laser scanning speed $(v)$, to reduce the formation of powder clustering in the initial layers of LPBF-processed Ti-6Al-4V. Such observations urge the need for support topology optimization, taking into consideration the factors like available area, loading, and constraint conditions [39]. (3) Reducing the overall production cost: The addition of support structures, compared to a solid support, decreases the overall fabrication cost because it is associated with a lower required amount of powder as well as post-process operations. In general, the main focus of the currently available support generator tools has been to decrease the amount of required supports and offer faster, cheaper, and more efficient AM processing [55,56]. These well-known and commercially available support generator software include Magics (Materialize, Michigan, USA), Sunata (Atlas 3D, Plymouth, IN), and 3DXpert (3DXpert, Rock Hill, SC). Generally, these packages offer several default support structure types for users with some control on the geometrical parameters of support structures (e.g., the wall thickness and gap). Due to the ease of use, these software packages have successfully been used by researchers in the LPBF design stage for generating support structures.

Overall the primary concern when designing support structures has always been to minimize the overall production cost and time, as well as lowering the risk factors associated with the fabrication, such as residual stress, the warping effect, and part collapse. However, no work has been conducted to enhance the quality of the as-fabricated main part through analyzing various factors including the microstructure behavior, material properties and fabrication cost. Inspired by this motivation, this study focused on the effect of support structure on the quality of parts considering the mentioned aspects. Specifically, the influence of support structure shape (i.e., Pin-type, Angled-type, Cone-type) and geometry (i.e., support wall thickness, and gap) was investigated on the composition, hardness, microstructure, and material/time consumption for LPBF-fabricated IN718 parts.

\section{Materials and Methods}

\subsection{Computer-Aided Design}

A total of seven main parts, each having a dimension of $8 \mathrm{~mm} \times 8 \mathrm{~mm} \times 4 \mathrm{~mm}$, were modeled using Solidworks (version 2018-2019, Dassault Systems, Waltham, MA, USA). To study the influence of support type, three different support structures of Angledtype, Cone-type, and Pin-type were considered. The chosen support structure types were amongst the most widely used available options in the commercial support generation tools (i.e., 3D systems 3DXpert, Materialize Magics, Atlas3D Sunata, Siemens NX). For 
an accurate comparison, a constant wall thickness of $\mathrm{T}=0.53 \mathrm{~mm}$ and gap distance of $\mathrm{G}=0.80 \mathrm{~mm}$ were considered (see Figure 1). Also, to evaluate the influence of the support geometry, four support structures of a particular type (i.e., angled-type) were designed by varying support wall thicknesses and gap distances in each of them. The angled-type support structure was chosen because it resembles the default support design selected by most of the aforementioned support generator software. This support structure is mostly used in software packages when the variation of the thickness is desired in support design. In all cases, the support structures had the overall dimension of $8 \mathrm{~mm} \times 8 \mathrm{~mm} \times 3 \mathrm{~mm}$. Table 1 summarizes the variation in the type of support structures, the corresponding support wall thickness $(\mathrm{T})$, and gap distance $(\mathrm{G})$. For ease of referencing, the samples were labeled with a customized method. For example, in the label AT33G100, 'A' stands for the 'Angled-type support', 'T33' stands for the wall thickness of $0.33 \mathrm{~mm}$, and 'G100' stands for the gap distance of $1.00 \mathrm{~mm}$. The supports were allocated to the main part along with the appropriate labeling using the Materialize Magics software (Materialize, Plymouth, MI, USA).

a)

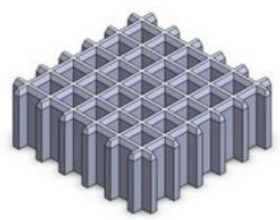

e)

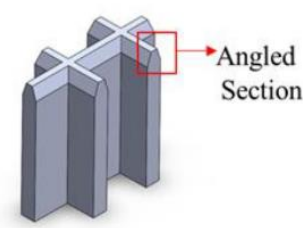

b)

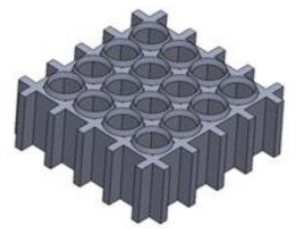

f)

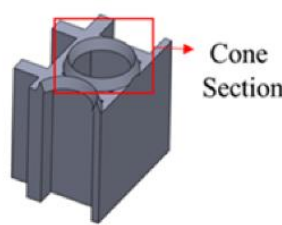

c)

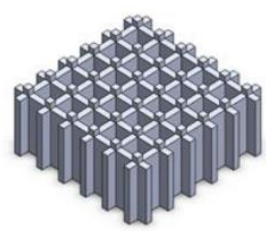

g)

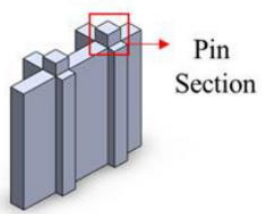

d)

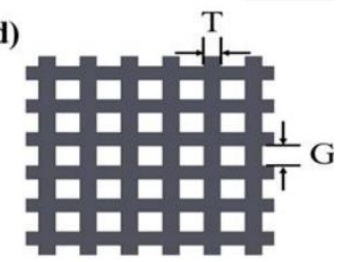

Figure 1. Computer-aided designs of the three different support structures: (a) angled-type (AT53G80), (b) cone-type (CT53G80), and (c) pin-type (PT53G80). (d) The thickness (T) and gap (G) of a support wall are presented from the top view. The cross-section view shows the contact area between the main sample and supports for (e) angled-type (AT53G80), (f) cone-type (CT53G80), and (g) pin-type (PT53G80).

\subsection{Powder Preparation and Fabrication}

IN718 powder was supplied from EOS GmbH (Krailling, Germany). The powder was sieved based on ASTM B214 [54] to avoid inhomogeneity in the distribution of particle size during fabrication. A scanning electron microscope (SEM) image of the fresh powder is presented in Figure 2a. The SEM analysis revealed that the powder had a spherical shape (the average circularity of 0.71), acceptable flowability and packing density, low impurity content, and excellent transformation ability. Moreover, the image was used for further analysis of the distribution of particle size using ImageJ software [57]. Figure $2 b$ represents a histogram for the particle-size distributions of fresh IN718 powders.

An EOS M290 metal 3D printer (EOS GmbH Electro Optical Systems, Germany) equipped with a $400 \mathrm{~W}$ Ytterbium fiber laser was used to fabricate the designed parts with three repetitions. The laser processing parameter set used for the fabrication were laser power $(P)$ of $285 \mathrm{~W}$, scanning speed $(v)$ of $960 \mathrm{~mm} / \mathrm{s}$, hatch spacing $(h)$ of $110 \mu \mathrm{m}$, and layer thickness $(t)$ of $40 \mu \mathrm{m}$, with an energy density $(E)$ of $67 \mathrm{~J} / \mathrm{mm} 3$, as calculated from the Equation (1) [58-60]. A stripe scanning strategy with a $67^{\circ}$ rotation angle in each consecutive layer was employed for all the parts.

$$
E=\frac{P}{h . v \cdot t}
$$


Table 1. Variation in the type and geometrical parameters of support structures. The abbreviation contained in the table has geometry type as the first letter followed by thickness and gap of the support geometry.

\begin{tabular}{|c|c|c|c|c|c|}
\hline $\begin{array}{l}\text { Sample } \\
\text { Number }\end{array}$ & $\begin{array}{l}\text { Support } \\
\text { Structure }\end{array}$ & Thickness (mm) & Gap (mm) & $\begin{array}{c}\text { Support } \\
\text { Label }\end{array}$ & $\begin{array}{c}\text { CAD } \\
\text { Design }\end{array}$ \\
\hline \multicolumn{6}{|c|}{ Variation in the type of support structures } \\
\hline 1 & Angled & 0.53 & 0.8 & AT53G80 & \\
\hline 2 & Cone & 0.53 & 0.8 & CT53G80 & \\
\hline 3 & Pin & 0.53 & 0.8 & PT53G80 & \\
\hline \multicolumn{6}{|c|}{ Variation in the wall thickness of support structures $(G=0.8)$} \\
\hline 4 & Angled & 0.33 & 0.8 & AT33G80 & \\
\hline 5 & Angled & 0.8 & 0.8 & AT80G80 & \\
\hline \multicolumn{6}{|c|}{ Variation in the wall thickness of support structures $(G=1)$} \\
\hline 6 & Angled & 0.33 & 1 & AT33G100 & \\
\hline 7 & Angled & 0.6 & 1 & AT60G100 & \\
\hline
\end{tabular}

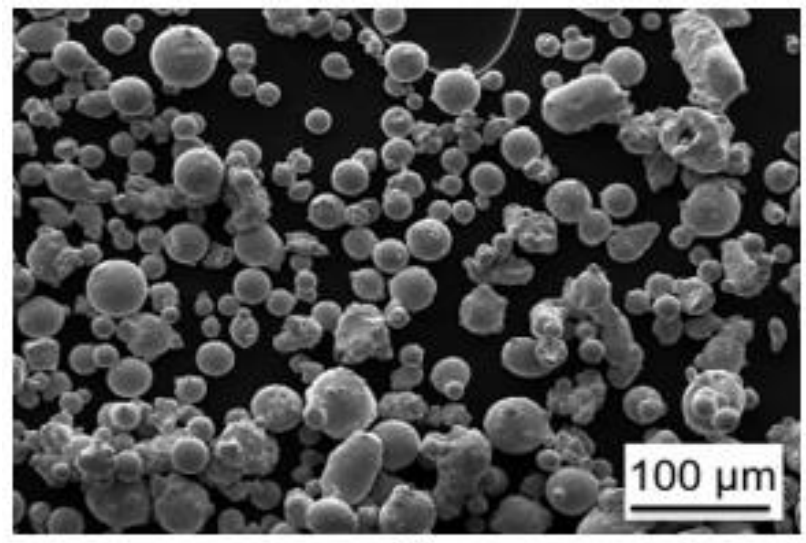

(a)

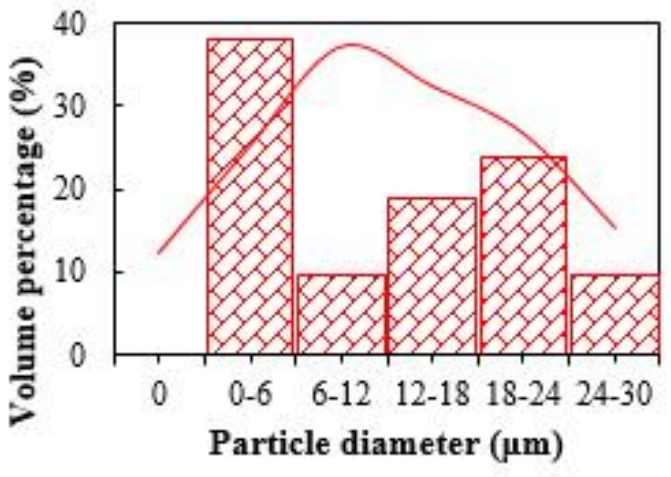

(b)

Figure 2. (a) SEM micrograph of the sieved IN718 powder; (b) particle size distribution of commercial EOS IN718 sieved powders.

\subsection{Sample Preparation}

The main samples were removed from the allotted support structures using the Wells No. 12 metal cutting bandsaw (Wellsaw, Three Rivers, MI, USA). An Allied Techcut 4 precision cutter (Allied High Tech, Compton, CA, USA) was then used to cut the bottom portion of the main samples $1 \mathrm{~mm}$ above the support/part interface through a plane normal to the building direction. The speed of the cutter blade was set at 100 RPM to obtain a 
uniform cut. The schematic of the cutting strategy is presented in Figure 3. The polished surface and the surface used to perform XRD and the hardness analysis are as shown in Figure $3 \mathrm{~d}$.

a)

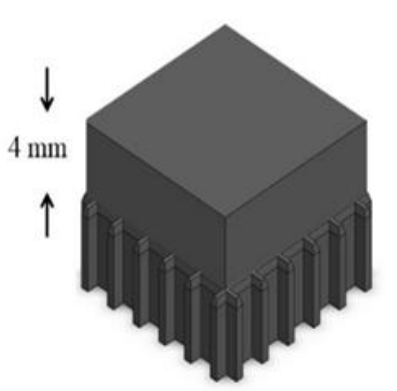

d)

top isometric view: b)

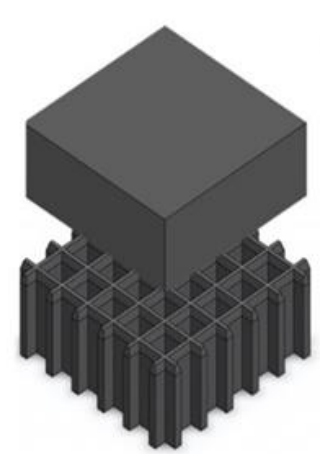

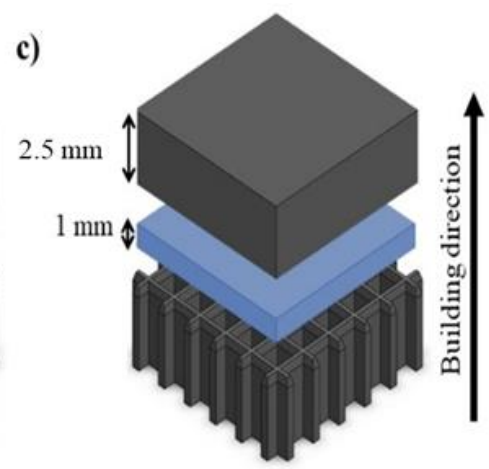

bottom isometric view:
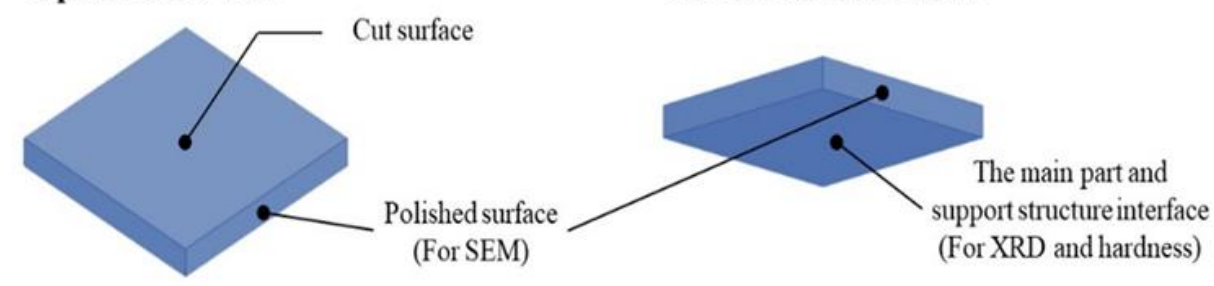

Figure 3. The schematic of (a) the fabricated main part on top of the allocated support structure, (b) the main part separated from the support structure, (c) the sectioning of the main part at $1 \mathrm{~mm}$ above the support/part interface through a plane normal to the building direction $(0.5 \mathrm{~mm}$ reduction equal to the thickness of the cutter blade has been considered), and (d) the different views of the sectioned portion demonstrating the employed surfaces for the SEM and XRD characterization.

After this step, the side surface of the cut sample, as shown in Figure 3, was set in resin and polished using the Allied E-PREP $4^{\mathrm{TM}}$ Grinder/Polish machine (Allied High Tech, Compton, CA, USA). The samples were initially polished using sandpaper of grits 180 to 1200 with water as a lubricant. Next, the samples were polished with a 'DiaMat' polishing cloth with $1 \mu \mathrm{m}$ polycrystalline diamond suspended solution, followed by 'Red Final C' polishing cloth with $0.05 \mu \mathrm{m}$ colloidal silica solution. The samples and polisher components were cleaned with distilled water before every cycle and blown by compressed air to remove any debris. The samples were etched with Kalling's reagent before performing SEM analysis.

\subsection{Experimental Procedure}

The crystallographic analysis of the bottom surface (i.e., side facing the supports, as shown in Figure 3) of the as-built samples was determined using Bruker D8 Advance $\mathrm{X}$-ray diffractometer (Bruker, Germany). The X-ray source was Copper $(\mathrm{Cu}) \mathrm{k}$-alpha, and the measurements were conducted at room temperature where the wavelength of $\mathrm{X}$-rays was $1.5406 \AA$, step intervals of 0.02 and in $2 \theta$ between $35^{\circ}$ and $100^{\circ}$. Vickers hardness analysis was performed with the help of a LECO LM 300 Vickers Hardness tester (LECO co., St. Joseph, MI, USA) on the bottom surface (i.e., side facing the supports, as shown in Figure 3) of the cut specimen. The test was conducted under $500 \mathrm{~g}$ loads applied for $10 \mathrm{~s}$ based on the ATSM E92-82 standard [61]. Five indentations were done for each sample, including the areas near and far from the edges at the interface plane (See Figure 3). It should be noted that the interface plane was selected for taking the measurements as this plane is affected directly by the support structures, without getting influence from the epitaxial growth occurring along the building direction. Moreover, consistency between $\mathrm{XRD}$ and hardness requires generating results at the same plane. In this case, the average 
hardness value for each sample was reported for the interface plane. To evaluate the effect of support structures on the microstructure of the fabricated parts, a Hitachi S-3000N Variable Pressure SEM was used. To be able to investigate the effect of support structure on the depth of the melt pools, the side surface closer to the support zone (i.e., polished side surface, as shown in Figure 3) was selected for the SEM analysis and the dimensional analysis was performed according to the NASA MSFC-SPEC-3717 Standard [62]. It should be mentioned that, as the goal of study is evaluating the effect of support structure on the microstructure, the melt pool analysis was performed on the first few layers manufactured on top of the support structures (See Figure 3). Using the same equipment, energy dispersive X-ray spectroscopy (EDS) was performed on the samples to evaluate the compositional analysis. The microstructure features (i.e., melt pool), hardness, and composition of all the samples were evaluated and compared.

\subsection{Cost Model}

The total cost of fabricating a part was estimated by considering the direct raw material cost, the indirect cost, and the fixed cost [63]. Specifically, the direct raw material cost referred to the raw material purchase cost that was calculated based on the raw material market price $P_{\text {raw material }}(\mathrm{USD} / \mathrm{g}$ ) and the weight of the part $w$ including both the main part and the support structure, calculated as follows.

$$
w=\rho_{\text {raw material }} \times\left(V_{\text {build }}+V_{\text {support }}\right) \times\left(1+r_{\text {loss }}\right)
$$

$\rho_{\text {raw material }}$ is the density of the raw material $\left(\mathrm{g} / \mathrm{mm}^{3}\right), V_{\text {build }}$ is the main part volume $\left(\mathrm{mm}^{3}\right), V_{\text {support }}$ is the support volume $\left(\mathrm{mm}^{3}\right)$, and $r_{\text {loss }}$ is the material loss rate.

The indirect cost referred to all time-dependent costs that were associated with the capital investment and the fabrication process including the consumables like compressed air, Argon gas, and filters. The fixed $\operatorname{cost} C_{\text {fixed }}$ was defined as all the fixed costs for each fabrication including machine setup and maintenance. The total cost was formulated as Equation (3).

$$
C_{\text {total }}=\left(\dot{C}_{\text {indirect }} \times T_{\text {build }}\right)+C_{\text {fixed }}+w \times P_{\text {raw material }}
$$

In this equation, $T_{\text {build }}$ denotes the total build time (hr) for fabricating the entire part and is estimated by using the machine control software EOSPRINT 2.0 in this research. $T_{\text {build }}$ is consisted of the time for fabricating the main part $T_{\text {main part }}$ and the time for fabricating the support structure $\left(T_{\text {support }}\right)$. The $\dot{C}_{\text {indirect }}$ refers to the indirect cost rate (USD/hr) and it was calculated using the equation below.

$\dot{C}_{\text {indirect }}=\dot{C}_{\text {air }}+\dot{C}_{\text {Argon }}+\dot{C}_{\text {filter }}+\dot{C}_{\text {blade }}+\left(C_{\text {machine }} / N_{\text {machine }}+C_{\text {occupancy }}+C_{\text {Maintenance }}\right) / M+\left(E_{\text {build }} \times P_{\text {energy }}\right)$

In this equation, $\dot{C}_{a i r}$ is the cost rate of the compressed air (USD/hr), $\dot{C}_{\text {Argon }}$ is the cost rate of the Argon gas consumption (USD/hr), $\dot{C}_{\text {filter }}$ is the cost rate of filter usage (USD/hr), $\dot{C}_{\text {blade }}$ is the cost rate of the blade usage (USD/hr), $C_{\text {machine }}$ is the purchasing cost (USD), $N_{\text {machine }}$ is the lifetime of the machine (year), $C_{\text {occupancy }}$ is the occupancy cost per year (USD/year), $C_{\text {Maintenance }}$ is the maintenance cost per year (USD/year), $M$ is the maximum capacity of the machine $(4,000 \mathrm{hrs} /$ year $), E_{\text {build }}$ is total energy consumption per build $(\mathrm{kW})$ and $P_{\text {energy }}$ is the average price of electricity (USD $/ \mathrm{kWh}$ ).

In addition, the fixed cost was calculated by considering the labor cost for machine setup and the cost of replacing and refinishing the build platform.

$$
C_{\text {fixed }}=C_{\text {setup }} \times t_{\text {setup }}+C_{\text {Platform }} / N_{\text {use }}+C_{\text {Refinishing }}
$$

$C_{\text {setup }}$ is the salary of the labor (USD/hr), $t_{\text {setup }}$ is the time required to setup the machine, $C_{\text {Procument }}$ is the build platform price (USD), $N_{\text {use }}$ is the total number of runs per 
build platform, and $C_{\text {Refinishing }}$ is the platform refinishing cost. Parameters' values that are used in the cost calculation are shown in Table 2.

Table 2. List of parameters' values used in the cost calculation.

\begin{tabular}{|c|c|c|}
\hline Symbol & Definition & Values \\
\hline \multicolumn{3}{|c|}{ Indirect cost } \\
\hline$\dot{C}_{a i r}$ & The cost rate of the compressed air & 0.00 (USD/hour) \\
\hline$\dot{C}_{\text {Argon }}$ & The cost rate of Argon gas & 14.77 (USD/hour) \\
\hline$\dot{C}_{\text {filter }}$ & The cost rate of the filters & 0.56 (USD/hour) \\
\hline$\dot{C}_{\text {blade }}$ & The cost rate of the blade & 1.65 (USD/hour) \\
\hline$C_{\text {machine }}$ & The capital investment of the AM machine & $125,941.71$ (USD) \\
\hline$N_{\text {machine }}$ & The useful life of the AM machine & 7 (year) \\
\hline Coccupancy & The occupancy cost rate of the AM machine & 3616.04 (USD/year) \\
\hline$C_{\text {Maintenance }}$ & The yearly maintenance cost of the AM machine & 30769.23 (USD/year) \\
\hline$M$ & The yearly utilization capability of the AM machine & 4000.00 (hour/year) \\
\hline$E_{\text {build }}$ & The total energy consumption per build & $2.40(\mathrm{~kW})$ \\
\hline$P_{\text {energy }}$ & The electricity price & $0.10(\mathrm{USD} / \mathrm{kWh})$ \\
\hline$C_{\text {setup }}$ & $\begin{array}{c}\text { Fixed cost } \\
\text { The labor hourly salary }\end{array}$ & 30.77 (USD/hour) \\
\hline$t_{\text {setup }}$ & The machine setup time for each build & 3 (hour) \\
\hline$C_{\text {Platform }}$ & The cost of the build platform & 275.00 (USD) \\
\hline$N_{\text {use }}$ & The maximum number of uses of the build platform & 20 \\
\hline$C_{\text {Refinishing }}$ & The refinishing cost of the build platform & 38.46 (USD) \\
\hline$\rho_{\text {raw material }}$ & The density of the raw material & $8150.00(\mathrm{~g} / \mathrm{mm} 3)$ \\
\hline$r_{\text {loss }}$ & The material loss rate & $20.00 \%$ \\
\hline$P_{\text {raw material }}$ & $\begin{array}{l}\text { Direct raw material cost } \\
\text { The purchase cost of the raw material }\end{array}$ & $0.13(\mathrm{USD} / \mathrm{g})$ \\
\hline
\end{tabular}

\section{Results and Discussion}

\subsection{XRD and EDS Analysis}

The XRD diffractograms of the as-built IN718 main sample revealed the presence of $\gamma, \gamma^{\prime}$ and $\gamma^{\prime \prime}$ phases over the $2 \theta=35-100$ as shown in Figure 4. The $\delta$ and MC-type carbide phases were not detected in the XRD patterns as Seede et al. [64] showed the volume ratio of these phases in as-fabricated IN718 samples are minor and nondetectable with commercially available XRD instruments. As it is represented some of the peaks $\left(\gamma, \gamma^{\prime}, \gamma^{\prime \prime}(220)\right.$ and $\left.\gamma, \gamma^{\prime}(311) / \gamma^{\prime \prime}(033)\right)$ are asymmetric, which is also reported in the literature [65]. This observation can be attributed to two mechanisms: the dislocation distributions resulting in elastic strains $[66,67]$ and variation in lattice parameters due to the compositional gradients in the microstructure of the samples [65]. However, more investigation is needed to explore this phenomenon, which is beyond the focus and goal of this study. In all the seven samples, the $\gamma, \gamma^{\prime}(111) / \gamma^{\prime \prime}(112)$ phases make up the dominant peak. Three phases of $\gamma^{\prime \prime} \mathrm{Ni3Nb}$ with a D022 ordered body-centered tetragonal (bct) crystal structure, $\gamma^{\prime} \mathrm{Ni3}(\mathrm{Al}, \mathrm{Ti})$ with a L12 ordered face-centered cubic (fcc) crystal structure and $\gamma(\mathrm{Ni}-\mathrm{Cr}-\mathrm{Fe}-\mathrm{C})$ in a face-centered cubic (fcc) crystal structure was detected for the main peak. The $\gamma^{\prime}$ and $\gamma^{\prime \prime}$ are two main secondary phases known as the precipitation hardening phases of IN718 [68]. The next dominant peak was $\gamma, \gamma^{\prime}, \gamma^{\prime \prime}(200)$ where overlapping of peaks exhibits the formation of precipitates parallel to the building direction which is one of the features of LPBF parts $[35,64,69]$. 


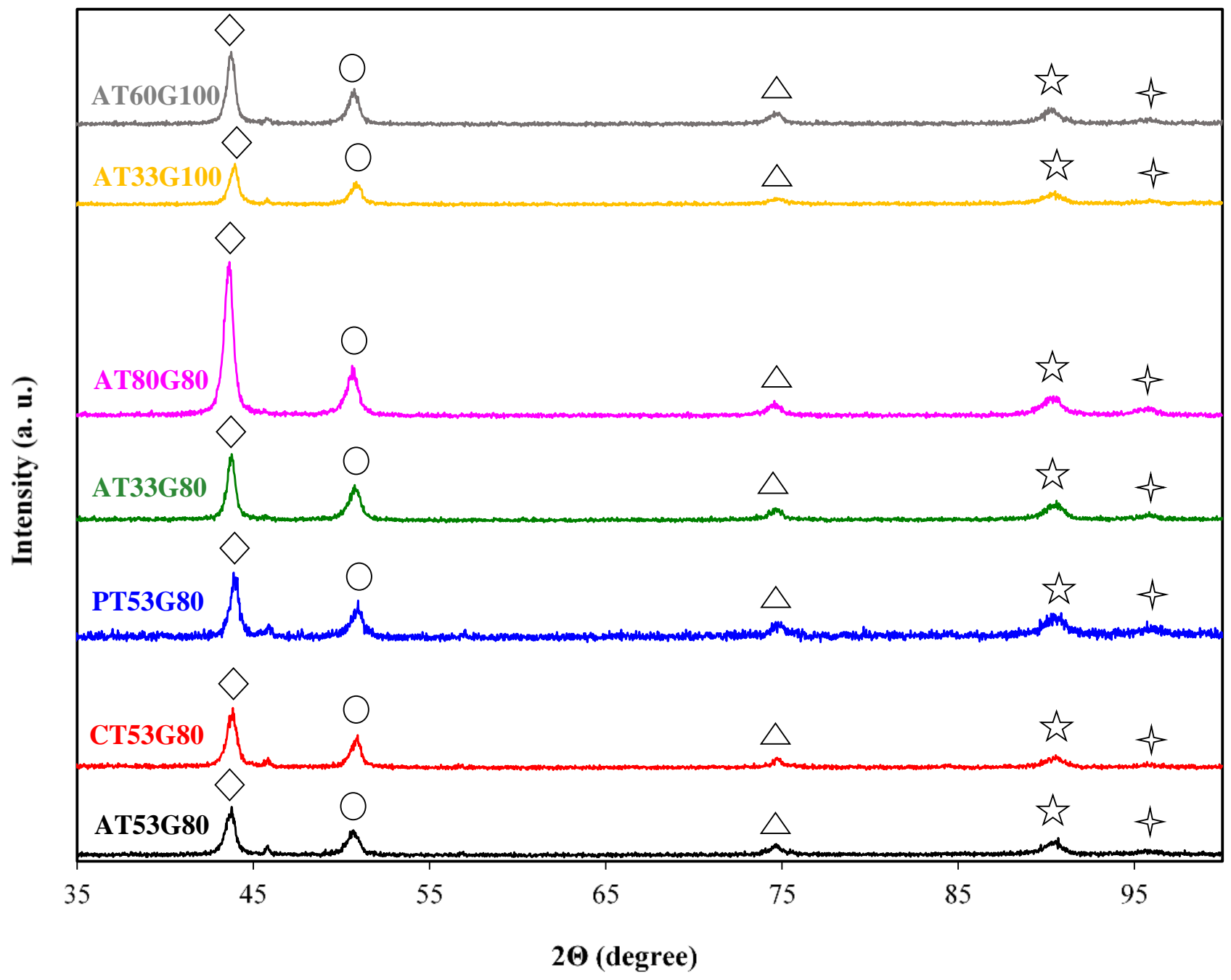

Figure 4. XRD diffractograms for the Inconel 718 main parts fabricated on top of different support structures. The $\gamma, \gamma^{\prime}$ phases were coincident at (111), (200), (220). The symbols are defined as follows: $\gamma, \gamma^{\prime}(111) / \gamma^{\prime \prime}(112): \diamond ; \gamma, \gamma^{\prime}, \gamma^{\prime \prime}(200)$ :

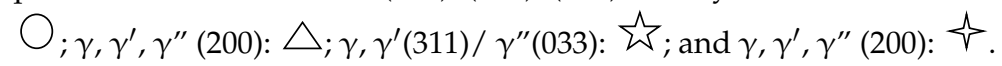

To have a more accurate characterization of $\gamma, \gamma^{\prime}$ and $\gamma^{\prime \prime}$ phases, a smaller range of $2 \theta\left(42-45^{\circ}\right)$ was represented in Figure 5. As it is shown, once the different type of the support structures was concerned, the Pin-type (PT53G80) presented a broader and shallower diffraction peak compared to the other two types (CT53G80 and AT53G80). Also, reduction in the thickness of the supports resulted in shallower peaks when the samples fabricated on top of AT60G100 and AT80G80 supports were compared with the samples supported by AT33G100 and AT33G80, respectively. A similar trend was observed when the gap parameter $(G)$ increased, with a considerable drop in peak intensity being detected for the sample supported by AT33G100 compared to the sample fabricated with AT33G80 support.

In terms of the position of the peak angle, we can see that there is a variation for the $\gamma$ (111) diffracted angle between samples. The $2 \theta$ location of the detected $\gamma$ peaks is listed in Figure 6. When comparing the samples fabricated with different types of supports, the highest increase in the diffraction angle can be seen for the Pin-type support (PT53G80), followed by the cone-type (CT53G80). The geometrical parameters (i.e., thickness and gap)

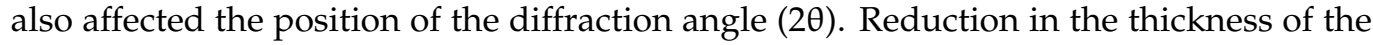
supports (T) led to the increase in the diffraction angle, for both cases of AT80G80 and AT33G80, and AT60G100 and AT33G100. By comparing the AT33G100 and AT33G80, it was found out that a decrease in the gap value reduced the angle of diffraction. 


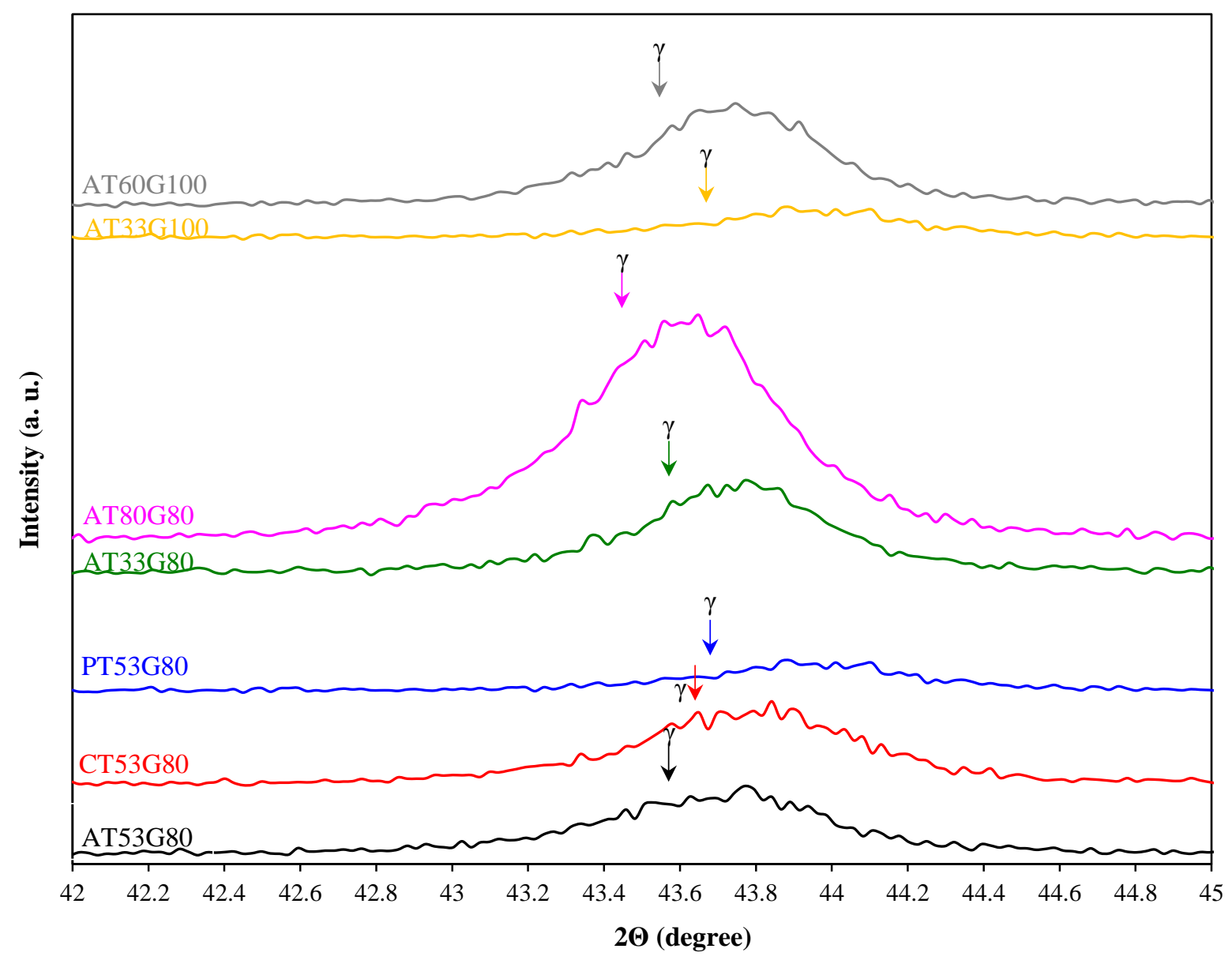

Figure 5. The variation in the $\gamma(111)$ peak position in the XRD diffractograms extracted for the samples.

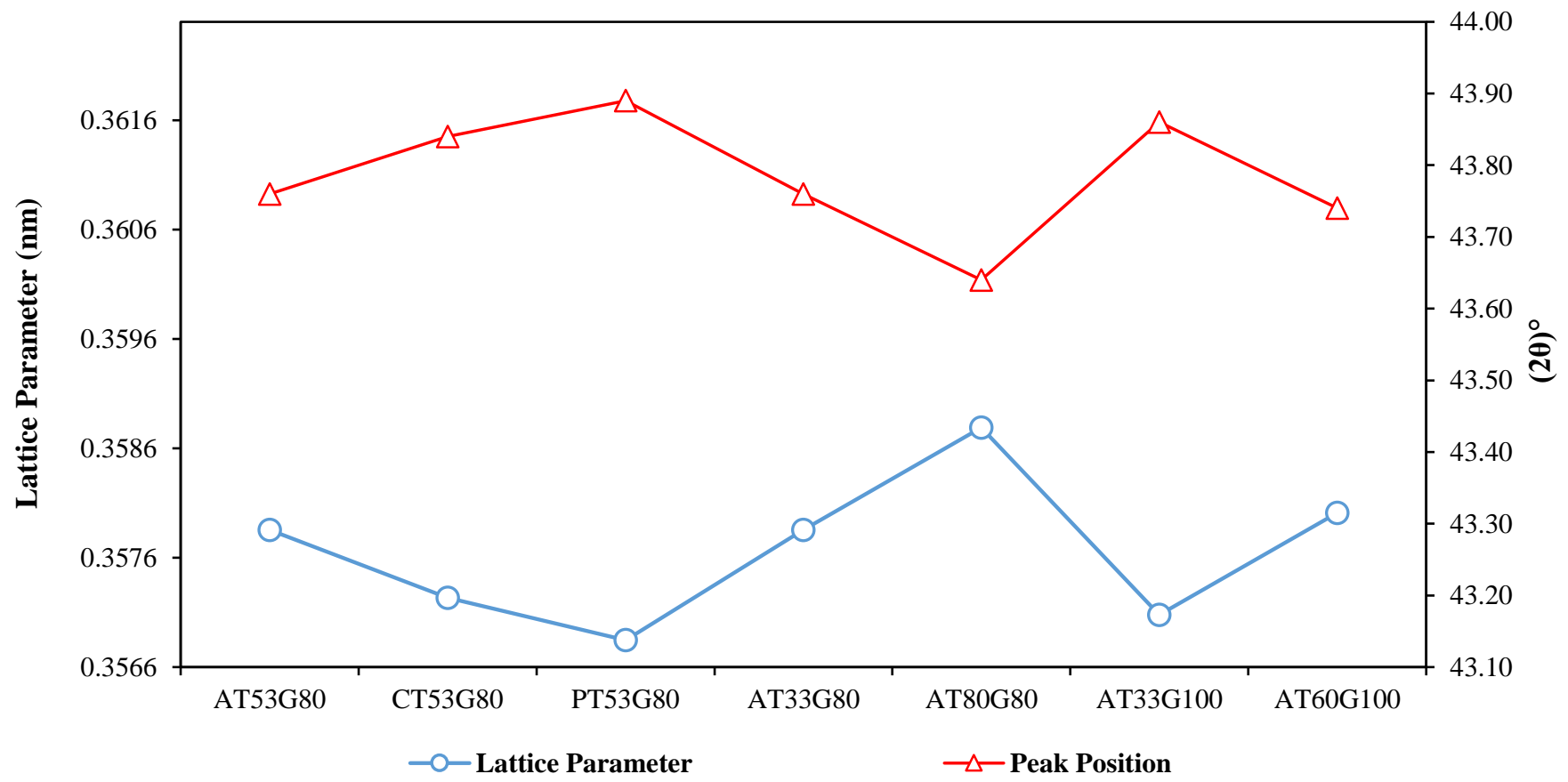

Figure 6. The displacement of identified $\gamma(111)$ peaks and the lattice constant of the $\gamma$ phase extracted from the XRD diffractograms of IN718 samples fabricated on top of different support structures. 
Based on the variation observed for the diffraction angle, the lattice parameter can be calculated for each sample using the Bragg's law equation which relates the interplanar distance and the lattice parameter:

$$
n \lambda=2 d \sin \theta
$$

where, $\lambda$ is the wavelength of the X-ray used in the XRD analysis, $\mathrm{d}$ is the interplanar distance and $\theta$ is the angle of diffraction.

Figure 6 shows the lattice parameter values determined for each sample. Among the samples fabricated with different types of supports, the highest lattice parameter $(0.35822 \mathrm{~nm}$ ) belongs to the samples fabricated with the Angled-type supports (AT53G80) and the lowest lattice parameter $(0.35729 \mathrm{~nm})$ belongs to the Pin-type supports (PT53G80). Also, in terms of geometrical parameters of the supports, the highest value of lattice size $(0.3592 \mathrm{~nm})$ belonged to the sample fabricated on the densest support with higher thickness and less gap value (AT80G80). Conversely, the sample supported by AT33G100 with the lowest thickness and highest gap, was formed by unit cells with smaller size. Therefore, as the dissolution of secondary phases into the $\gamma$ phase leads to an increase in the size of the lattice parameter of the matrix phase, it can be inferred that the sample supported by the angled-type (AT53G80) experienced the higher level of dissolution of secondary phases, but the formation of less precipitates. By contrast, the lowest lattice size belonged to the sample with pin-type support which shows a higher level of precipitation of secondary phases. The same comparison can be done for the samples fabricated on angled-type support with different geometrical parameters. In this case, the sample fabricated on the support with a lower gap value (AT33G80) had a higher lattice size compared to the sample supported by the higher gap value (AT33G100). This brings about more dissolution but less precipitation for the former. When it comes to the effect of thickness, by comparing the samples supported by AT80G80 and AT33G80, higher thickness value resulted in higher lattice parameter size and in turn higher level of dissolution but less amount of precipitation of secondary phases. The same trend can be seen for the samples fabricated by AT60G100 and AT33G100 supports. This observation can be attributed to the heat transfer and cooling rate conditions vary among different types of support structures. It has been revealed that a higher cooling rate reduces the precipitate formation which leads to reduced precipitation hardening [70]. Since the area of contact between the support and the main part is directly proportional to the amount of heat conducted during the fabrication process, cooling rate and heat dissipation were affected by the type and shape of the support structure. To compare the level of energy dissipation via different support structure, the bottom and top area of the different supports which were in contact with the building plate and main part respectively are presented in Table 3. As the area of contact between the support structure and main part (top area) increased in order (PT53G80 < CT53G80 < AT53G80), the cooling rate of the supports would be increased according to the Fourier law of heat conduction [71]. The highest and lowest cooling rate can be estimated for the angled-type and pin-type supports owing to lesser and more precipitation on the samples fabricated with the respective supports. This can also be corroborated by the increasing volume of the supports with PT53G80 having the lowest volume and AT53G80 having the highest. As the volume of the support structure increases, more material will be present underneath to absorb the heat from a sintered layer of the part. Furthermore, AT80G80 with a higher thickness value and then higher contact area compared to AT33G80 resulted in the fabrication of samples with lower and higher amounts of precipitates, respectively. The same conclusion is true when AT33G100 and AT60G100 are compared. In terms of the effect of gap value, a higher level of precipitation can be expected for the AT33G100 with less contact area compared to AT33G80. It should be noted that this variation in the proportion of phases and precipitation levels can bring about different mechanical properties such as strength and ductility and then should be adjusted based on the desired application. Using the proper type of support structure, as observed here, can play a more important role to control the properties of the as-fabricated part. 
Table 3. The top area, bottom area, and support volume for different support structures.

\begin{tabular}{cccc}
\hline Sample & Top Area $\left(\mathbf{m m}^{\mathbf{2}}\right)$ & Bottom Area $\left(\mathbf{m m}^{\mathbf{2}}\right)$ & Support Volume $\left(\mathbf{m m}^{\mathbf{3}}\right)$ \\
\hline AT53G80 & 28.18 & 40.77 & 120.46 \\
CT53G80 & 11.30 & 40.77 & 115.49 \\
PT53G80 & 10.08 & 40.77 & 113.11 \\
AT33G80 & 16.87 & 33.20 & 92.43 \\
AT80G80 & 38.69 & 48.00 & 142.63 \\
AT33G100 & 12.97 & 27.76 & 81.10 \\
AT60G100 & 28.00 & 39.00 & 115.11 \\
\hline
\end{tabular}

Table 4 lists the EDS measured chemical compositions at the core of columnar dendrites that were obtained from identical samples with different support structures. As revealed from Table 4, the Ni element content has the highest value of $57.3 \mathrm{wt} . \%$ in the pin-type supported sample (PT53G80). This rate was dropped considerably for the angled-type support (AT53G80) with existing of the other elements being observed. Jia and Gu [19] found out that the Ni content increased by the increase in the energy input during the LPBF process of IN718 samples. A similar trend was observed in this study, as the highest Ni percentage can be seen for the sample fabricated on support with less contact area, which results in lower heat dissipation rate and thus longer heat accumulation (PT53G80). This condition resembled the fabrication of samples with a higher level of energy density. In terms of the effect of thickness, the same trend was observed by comparing the samples fabricated with AT33G80 and AT80G80 supports. A 5.5 percentage drop in Ni content was found for the sample fabricated on thicker support, which can be attributed to the larger contact area and higher cooling rate. However, the Ni content didn't change when the thickness increased from $0.33 \mathrm{~mm}$ in AT33G100 to $0.60 \mathrm{~mm}$ in AT60G100. Increasing the gap, however, increased the Ni content by more than 4 percent, which can be explained using the same logic discussed.

Table 4. EDS analysis showing chemical compositions at the core of columnar dendrites of LPBFprocessed Inconel 718 parts fabricated using different support structures.

\begin{tabular}{ccccc}
\hline \multirow{2}{*}{ Sample } & \multicolumn{3}{c}{ Elements } \\
\cline { 2 - 5 } & $\mathbf{N i}$ & $\mathbf{C r}$ & $\mathbf{F e}$ & $\mathbf{T i}$ \\
\hline AT53G80 & 46.1 & 17.6 & 16.1 & 1.0 \\
CT53G80 & 52.9 & 23.6 & 20.8 & 2.5 \\
PT53G80 & 57.3 & 21.1 & 20.3 & 1.2 \\
AT33G80 & 50.3 & 19.4 & 17.4 & 1.1 \\
AT80G80 & 44.8 & 16.3 & 14.2 & 1.2 \\
AT33G100 & 54.6 & 20.4 & 18.5 & 1.2 \\
AT60G100 & 54.5 & 20.6 & 18.5 & 1.2 \\
\hline
\end{tabular}

\subsection{Hardness Analysis}

The mechanical properties of all the seven main parts were evaluated in terms of Vickers microhardness at room temperature, as represented in Figure 7. For comparison, the hardness value of the wrought IN718 [based on the AMS 5663, [72] and cast IN718 [based on the AMS 5383 [73]] are also presented in the same figure. To evaluate the effect of support type on the hardness, the angled-type of support (AT53G80), cone type support (CT53G80), and pin type support (PT53G80) were compared. From Figure 7, as the lattice parameter decreased, the hardness of the samples increased for the samples fabricated with different types of support. The PT53G80 sample resulted in the highest hardness of $460.5 \mathrm{HV}$, while the AT53G80 and CT53G80 support yielded a hardness value of $354.6 \mathrm{HV}$ and $341.6 \mathrm{HV}$, respectively. This can be attributed to the different levels of secondary phases and precipitations explained in Section 3.1. It has been reported that the hardness of the IN718 alloy is dependent on the precipitation of two main secondary phases, $\gamma^{\prime \prime}$ and $\gamma^{\prime}$ 
phases [74]. Another study conducted by Chang et al. demonstrated that the $\gamma^{\prime}$ phase had a more significant role in the hardness of the as-fabricated IN718 [36]. In a similar study, Cao et al. [75] stated that a reduction in the strengthening phase leads to lower values of Vickers hardness. In agreement with the literature, the sample fabricated on top of the pintype support structure (PT53G80) had a higher portion of secondary phases resulted in a higher hardness value. Moreover, the significant increase in hardness for this sample can be attributed to the crystal and grain size of the main part. As mentioned in Section 3.1, due to the broader and shallower diffraction peak observed for the sample with PT53G80 support, finer grain size can be inferred based on the Scherrer equation [76]. Also, based on the HallPetch equation, there is an inverse relationship between the hardness and grain size [77], which explains the highest level of hardness for the sample with finer grain size supported by PT53G80. However, since some other factors such as the condition of distribution of $\gamma^{\prime \prime}$ particles and the size of this strengthening phase can also affect the hardness of IN718 alloy, more investigation is needed to find the exact phenomenon that resulted in a significant rise in the hardness of this sample. In terms of geometrical parameters, a similar effect can be observed in the thickness variation for the supports. The sample fabricated with lower thickness support (AT33G80) showed a higher hardness value compared to the one fabricated with thicker support (AT80G80), due to the difference in level of precipitates discussed. The same trend was seen for samples with AT33G100 and AT60G100. However, by comparing samples supported by AT33G100 and AT33G80, it was observed that the gap value does not affect the hardness value significantly. It should be noted that, regardless of the sharp increase observed for the sample fabricated with pin-type support, using AT33G80 and AT33G100 supports resulted in higher hardness compared to value reported for the post-processed IN718 samples, regardless of the fabrication technique $[74,78]$.

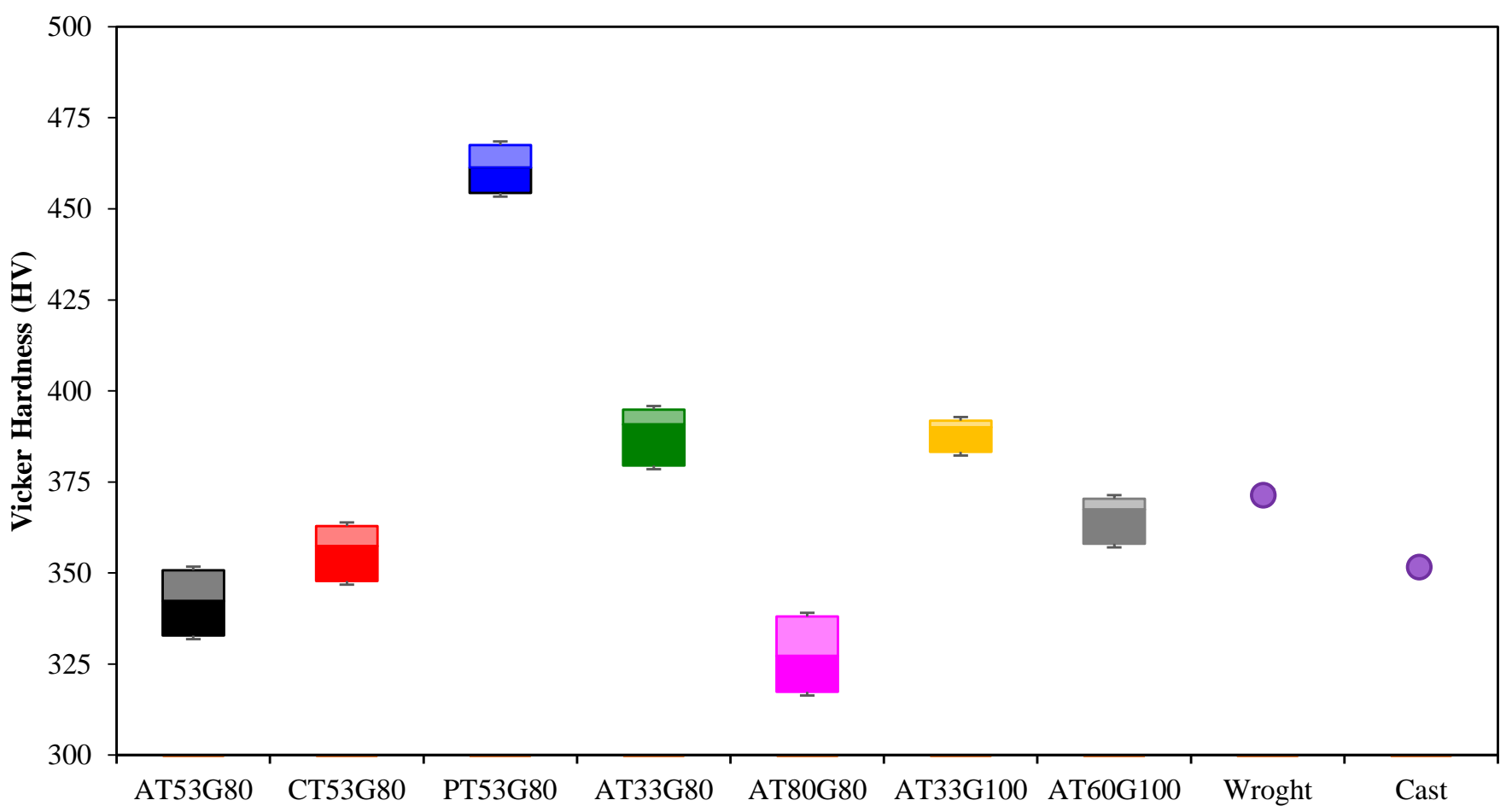

Figure 7. Vickers hardness evaluation of the LPBF-processed samples fabricated on top of support structures with different type and geometry. As reference, the Vickers hardness values of wrought IN718 (AMS 5663 [72]) and cast IN718 (AMS 5383 [73]) are also reported.

\subsection{Microstructural Analysis}

The SEM micrographs of the IN718 parts are presented in Figure 8. Figure 9 represents the results of the dimensional analysis performed on melt pool size for all the samples, 
with the depth of melt pools being calculated. Regardless of the variation in size, the average depth of the pools was found higher than the initial layer thickness for all the samples. This proves the overlapping of laser tracks resulting in overlapping of melt pools, which has been reported as one of the thermal behaviors of the LPBF technique [79-81]. According to the results, the pin-type (PT53G80) gives rise to the highest average melt pool depth of $\sim 79.1 \mu \mathrm{m}$ followed by cone-type (CT53G80) to $\sim 71 \mu \mathrm{m}$. However, the angled-type (AT53G80) showed the lowest average melt pool depth of $\sim 62 \mu \mathrm{m}$ in the fabricated sample. Therefore, as the contact area between the main part and the supports increased, shallower pools formed in the sample. This can be again attributed to the different thermal conditions and heat transfer rate experienced by the sample caused by different types of support used. A higher contact area between the main sample and support (see Table 3) facilitates heat dissipation through conduction and therefore faster solidification and less time for the molten material to penetrate into the deeper layers. This condition underwent by the sample with angled-type support causes the formation of shallower pools. Conversely, less contact area for the sample fabricated with pin-type support provides a better condition for flowing the molten material into underneath layers, re-melting these layers, and the overlapping of pools. This led to the formation of deeper pools in the microstructure of the sample. The observation is in agreement with previous studies where the formation of deeper pools was attributed to the numerous reheating cycles and laser overlapping [69]. It also has been reported that overlap between the melt pools associates with reheating cycles which acts similar to the heat treatment process. This causes more evenly dispersion of fine $\gamma^{\prime \prime}$ particles in the matrix $[15,32,70]$ which improves the hardness value. This is consistent with the higher hardness value observed for the sample fabricated on pin-type support, with deeper pools being revealed in its microstructure. When it comes to the effect of geometrical parameters on the melt pool dimensions, the influence of thickness can be observed by comparing samples supported by AT80G80 and AT33G80, and also AT33G100 and AT60G100. A slight increase in depth of the pools can be seen for AT33G80 compared to AT80G80, and AT33G100 as against AT60G100. As expected, depth of the pools is higher for samples fabricated with a lower thickness value (i.e., less contact area). Therefore, it is consistent with the logic discussed for the different types of supports. Comparing the pool depth of the samples supported by AT33G80 and AT33G100 revealed that the gap value didn't affect the dimension of pools considerably.

\subsection{Production Time and Cost Analyses}

The actual production time for fabricating specimens with different support structures remained the same $(32 \mathrm{~min}$ ) in this research. The production time refers to the actual fabrication time excluding the required post-processing time, and it is calculated based on print speed and build path length. In this paper, the print speed selected for different specimens is the same; and the total length of the build path is similar. That's the main reasons why production time remains the same for specimens studied in this paper. In practice, specimens with more complex structures will require longer post-processing time, which is not considered in this research.

The estimated production costs for different specimens are slightly different for specimens studied in this research. The detailed cost calculation results are shown in Table 5. It can be observed from the table that all specimens have the same fixed cost and indirect cost, because each fabrication requires the same machine setup and maintenance, and the same consumption of consumables (such as compressed air, Argon gas, and filters). The direct material cost, on the other hand, is contributed by the material price and the consumption of materials of parts as well as the support structures; the direct material cost for different specimens remain similar because these specimens have the same weights of the parts and similar weights of the support structures. This means that the production cost of a specific specimen remains the same when different support structures are used but these structures have the same weight (assuming other factors remain the same such as the 
values of process parameters), indicating promising opportunities to perform cost-aware support structure design.

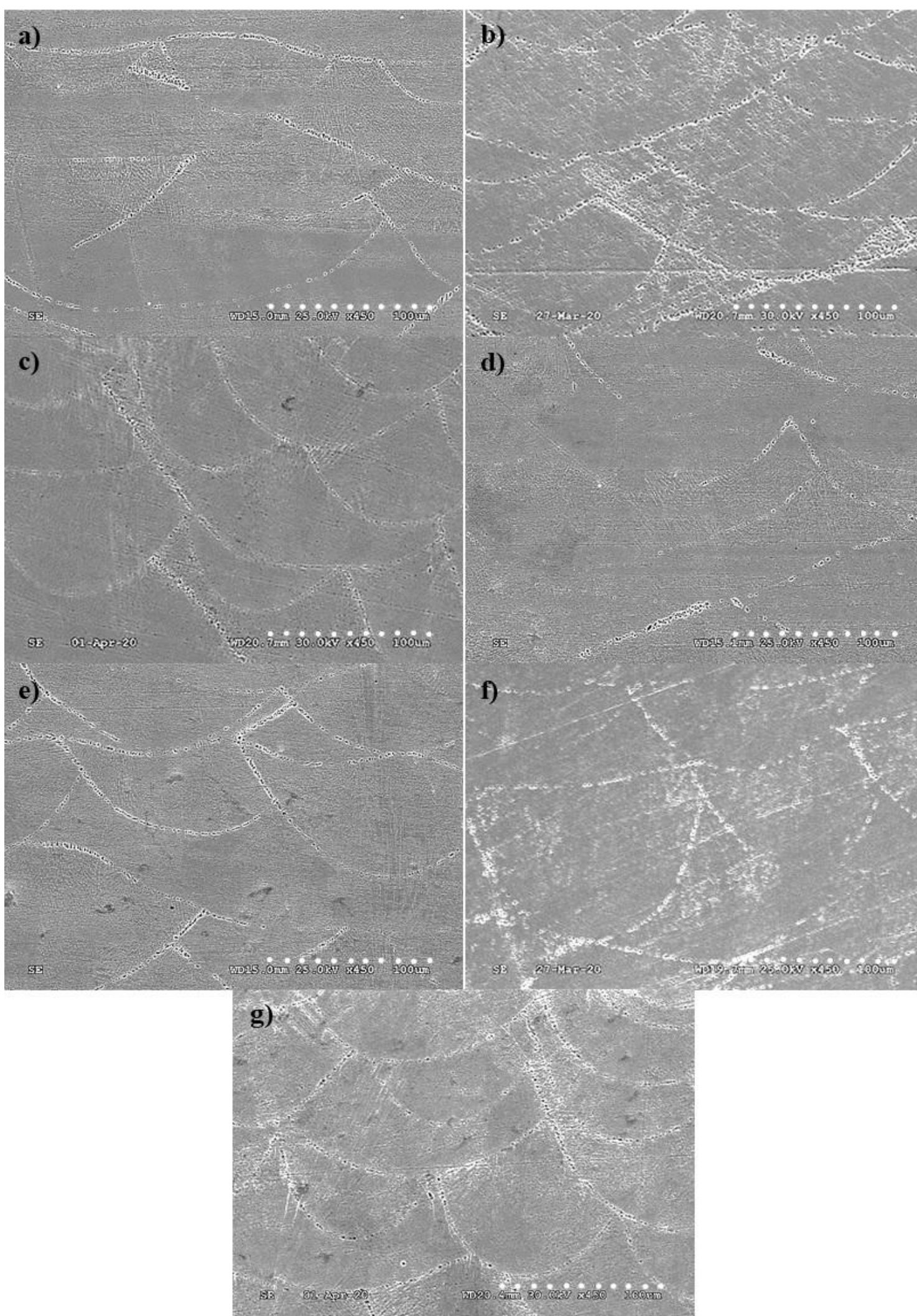

Figure 8. The SEM micrographs of the IN718 parts fabricated on top of different support structures: (a) AT53G80, (b) CT53G80, (c) PT53G80, (d) AT 33G80, (e) AT80G80, (f) AT33G100, and (g) AT60G100. 


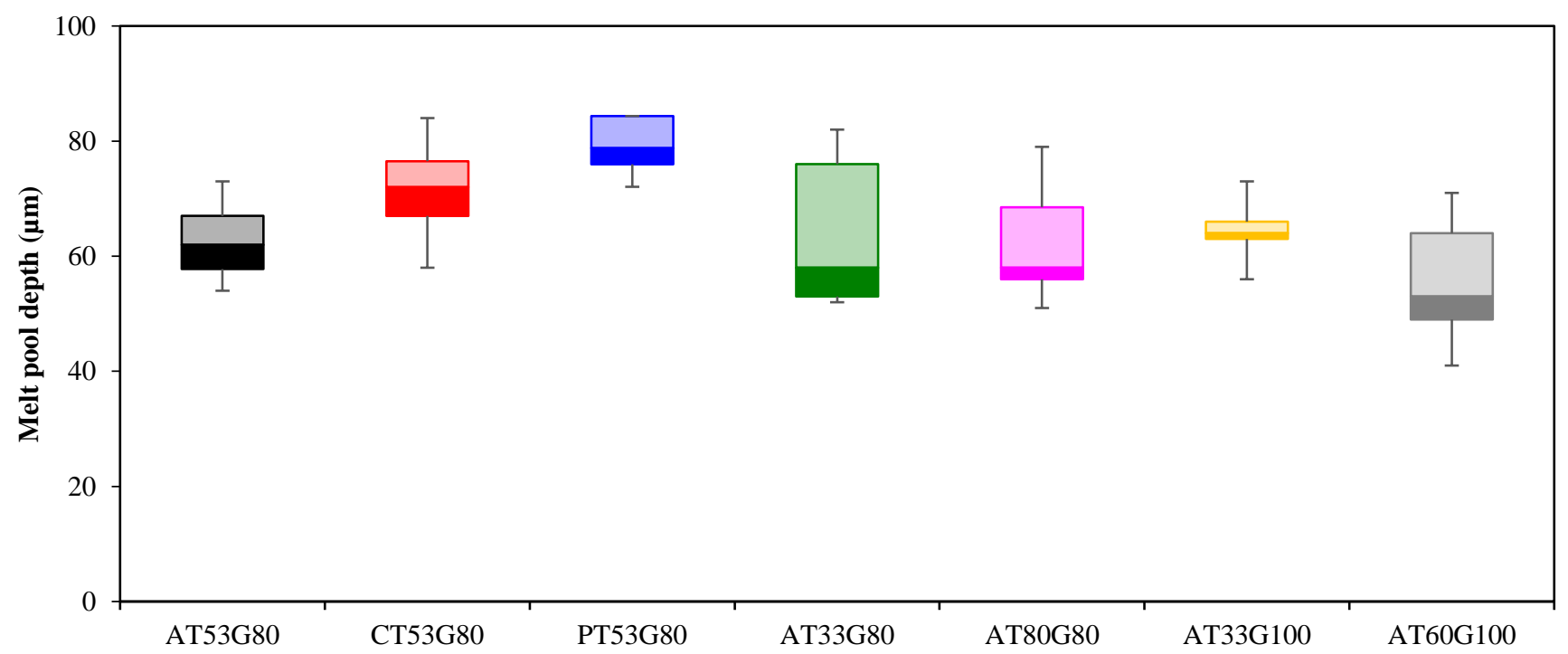

Figure 9. The melt pool depth of the IN718 LPBF parts fabricated on top of support structures with different types (AT53G80, CT53G80, PT53G80) and geometries (AT 33G80, AT80G80, AT33G100, AT60G100).

Table 5. The cost calculation results (cost: USD; volume: $\mathrm{mm}^{3}$ ).

\begin{tabular}{ccccccccc}
\hline Sample & $\begin{array}{c}\text { Main Part } \\
\text { Volume }\end{array}$ & $\begin{array}{c}\text { Support } \\
\text { Volume }\end{array}$ & $\begin{array}{c}\text { Total } \\
\text { Volume }\end{array}$ & $\begin{array}{c}\text { Main Part } \\
\text { Total Cost }\end{array}$ & $\begin{array}{c}\text { Support } \\
\text { Total Cost }\end{array}$ & $\begin{array}{c}\text { Total } \\
\text { Cost }\end{array}$ & $\begin{array}{c}\text { Total Fixed } \\
\text { Cost }\end{array}$ & $\begin{array}{c}\text { Total } \\
\text { Indirect Cost }\end{array}$ \\
Direct Cost
\end{tabular}

It can also be observed from Table 5 that different specimens have similar cost distributions among three cost components: fixed cost, indirect cost, and direct cost. As example of cost distribution among different cost components is shown in Figure 10 for specimen AT53G80. The cost calculation results in Figure 10 show that the fixed cost has the largest contribution at $84.17 \%$, the direct cost is around $15.55 \%$ of the total cost, and the material-related direct cost is only less than $1 \%$ of the total cost. This indicates that in AM practices, despite the fact that raw material powders seem to be expensive, the material cost can be neglected compared to other consumables and machine setup and maintenance. In addition, the cost distributions among the main part and the support structure are shown in Figure 11. Among samples with different support structure types and geometry, their contribution to the total cost is similar, ranging from $24.06 \%$ (AT33G100) to $35.78 \%$ (AT80G80). The reason for this difference is mainly due to the support structure geometry (both thickness and gap). In addition, samples AT53G80, CT53G80, and PT53G80 demonstrate similar cost performance, indicating that the support structure type (angled, cone, and pin) does not evidently alter the cost contributions between the main part and the support structure. 


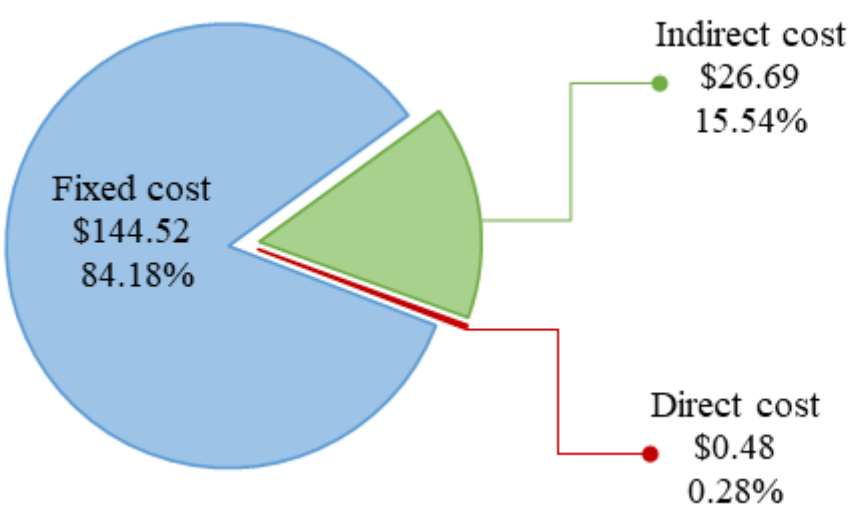

Figure 10. The cost distribution for specimen AT53G80.

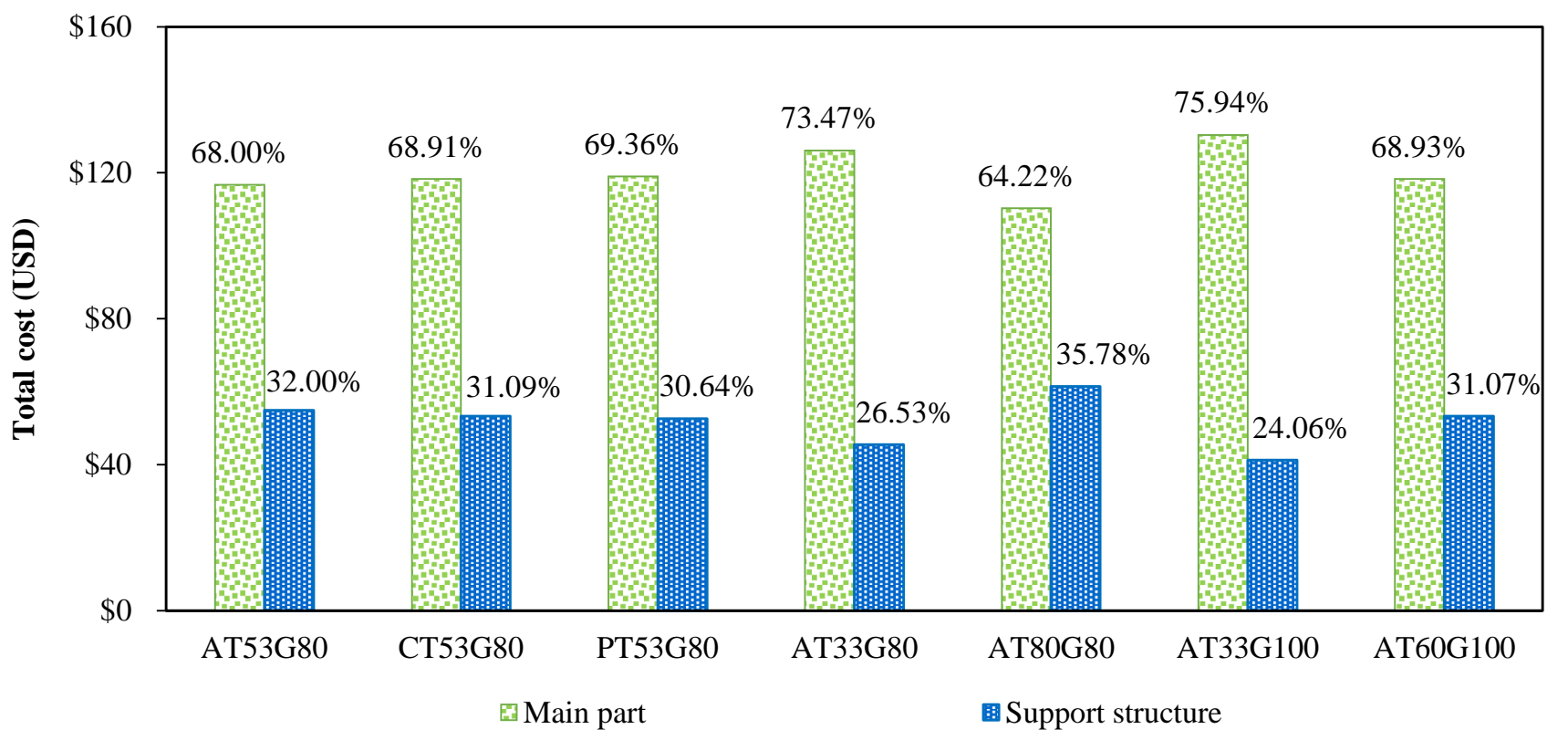

Figure 11. The total cost distribution between the main part and support structure for seven specimens.

Among seven samples, AT80G80 has the highest total cost of $\$ 171.71$ and the highest total support cost of \$61.44; AT80G80 demonstrates the lowest level of Vickers hardness (as shown in Figure 9). This indicates an interesting opportunity for improving the hardness level and reducing cost simultaneously. In addition, different types of the support structure (AT53G80, CT53G80, and PT53G80) show dramatically different levels of hardness (from around 330 to around 460 , indicating almost $40 \%$ improvement) but they have similar total costs (from $\$ 171.68$ to $\$ 171.69$ ). In other words, adjusting the type of support structure could achieve better hardness "for free". Next, we focus on the same support structure but different geometries, i.e., different thicknesses (AT53G80, AT33G80, and AT80G80; AT33G100 and AT60G100) and different gap (AT33G80 and AT33G100). Samples with different thicknesses demonstrate evidently different levels of hardness and different total support costs while having similar total costs. For example, AT80G80 (\$61.44) has around $35 \%$ more total support cost than AT33G80 (\$45.54), and AT80G80 also demonstrates a lower hardness (around 325) than AT33G80 (around 380). On the other hand, samples with different gaps have a similar level of hardness and similar costs. AT33G80 and AT33G100 have similar averaged hardness (around 380) with different standard deviations, and similar total cost and total support cost. 


\section{Conclusions}

The fabrication of IN718 samples through LPBF and the effect of support structures on the microstructure, composition, hardness, and fabrication cost of samples were studied. Seven identical samples supported by different types of support and different geometrical parameters were fabricated. Comparison between the properties and fabrication cost of samples revealed the following observations:

- Despite the presence of the same phases detected by XRD analysis in all the samples, the variation in the position of the diffracted peak angles and thus different lattice sizes were found for the specimens.

- Among the samples fabricated on different types of support, samples with pin-type (PT53G80) and angled-type (AT53G80) supports had the lowest and highest lattice size and therefore more and less level of precipitations, respectively. Also, in terms of geometrical parameters, the highest value of lattice size and the least precipitation level belonged to the sample fabricated on the densest support with higher thickness and less gap value (AT80G80). These observations were attributed to the heat transfer and cooling rate conditions among different types of support structures that arises from variation in the contact area between sample and support.

- It was revealed that the homogeneous or anisotropic behaviors of samples can be tailored using a proper type of support. In terms of the support type, the sample supported by pin-type (PT53G80) had the highest anisotropic behavior ratio among the samples. It was also found out that increasing the gap value as a geometrical parameter leads to more anisotropic behavior.

- The variation of the elements between samples was investigated using EDS Analysis. The lowest and highest Ni percentages were observed for the samples supported by Angled-type (AT53G80) and pin-type support (PT53G80), respectively. Also, increasing the gap increased the $\mathrm{Ni}$ content while no specific trend was observed for changing the thickness.

- Hardness of the samples varied among the samples fabricated with different types of support. A high microhardness value of $460.5 \mathrm{HV}$ was achieved in the as-fabricated IN718 sample built on top of a pin support structure. The results were comparable with the LPBF IN718 in the literature for as-fabricated LPBF sample (322 HV) [21], heat-treated LPBF ( $335 \mathrm{HV})$, heat-treated plus hot isostatic pressing (478 HV) [37], and as-fabricated wrought and cast (353 HV) [37].

- In terms of geometrical parameters, the sample fabricated with lower thickness support (AT33G80) showed a higher hardness value compared to the one fabricated with thicker support (AT80G80), However, it was observed that the gap value doesn't affect the hardness value significantly. This variation in hardness value was mainly attributed to the different levels of secondary phases and precipitations between samples.

- Among the samples fabricated with different types of support, the deepest melt pools were observed for the pin-type support (PT53G80).

- Regarding the influence of thickness, a converse relationship was found between the depth of the pools and the thickness value. It was also found out that change in the gap value doesn't change the dimension of pools considerably.

- Despite the fact that raw material powder seems to be expensive, the actual material cost is less than other consumables as well as machine setup and maintenance.

- Adjusting the support shape and geometry have the potential of enhancing the specimen properties without adding extra cost. Also, it is possible to increase the hardness and reduce the cost simultaneously.

- Samples fabricated with the same support structure but different geometries (e.g., different thicknesses) demonstrate different levels of hardness and different total support costs while having similar total costs. 
Author Contributions: Conceptualization, N.S.M., A.A. and Y.Y.; methodology, B.B.R., S.T., A.GR., B.F., M.H.; software, B.B.R., S.T., A.G.-R., B.F. and M.H.; validation, B.B.R., S.T., A.G.-R., B.F. and M.H.; formal analysis, B.B.R., S.T., A.G.-R., B.F. and M.H.; investigation, B.B.R., S.T., A.G.-R., B.F. and M.H.; resources, N.S.M., A.A. and Y.Y.; data curation; writing—original draft preparation, B.B.R., S.T., A.G.-R., B.F. and M.H.; writing-review and editing, N.S.M., A.A. and Y.Y.; visualization, N.S.M., A.A. and Y.Y.; supervision, N.S.M., A.A. and Y.Y.; project administration, N.S.M., A.A. and Y.Y.; funding acquisition, N.S.M. All authors have read and agreed to the published version of the manuscript.

Funding: This research was funded by University of Texas System STARs award.

Institutional Review Board Statement: Not applicable.

Informed Consent Statement: Not applicable.

Data Availability Statement: Not applicable.

Acknowledgments: This work was supported by a University of Texas System STARs award.

Conflicts of Interest: The authors declare no conflict of interest.

\section{References}

1. $\quad$ Lingenfelter, A. Welding of Inconel alloy 718: A historical overview. Superalloy 1989, 718, 673-683.

2. Metals, S. Inconel Alloy 718. Publication Number SMC-045. Special Metals Corporation 2007. Available online: https://www. specialmetals.com/documents/technical-bulletins/inconel/inconel-alloy-718 (accessed on 5 February 2021).

3. Hosseini, E.; Popovich, V.A. A review of mechanical properties of additively manufactured Inconel 718. Addit. Manuf. 2019, 30, 100877. [CrossRef]

4. Rahman, M.; Seah, W.K.H.; Teo, T.T. The machinability of inconel 718. J. Mater. Process. Technol. 1997, 63, 199-204. [CrossRef]

5. Thomas, A.; El-Wahabi, M.; Cabrera, J.M.; Prado, J.M. High temperature deformation of Inconel 718. J. Mater. Process. Technol. 2006, 177, 469-472. [CrossRef]

6. Çam, G.; Koçak, M. Progress in joining of advanced materials. Int. Mater. Rev. 1998, 43, 1-44. [CrossRef]

7. Liu, F.; Lin, X.; Huang, C.; Song, M.; Yang, G.; Chen, J.; Huang, W. The effect of laser scanning path on microstructures and mechanical properties of laser solid formed nickel-base superalloy Inconel 718. J. Alloys Compd. 2011, 509, 4505-4509. [CrossRef]

8. Chang, S.-H. In situ TEM observation of $\gamma^{\prime}, \gamma$ "and $\delta$ precipitations on Inconel 718 superalloy through HIP treatment. J. Alloys Compd. 2009, 486, 716-721. [CrossRef]

9. Izquierdo, B.; Plaza, S.; Sánchez, J.; Pombo, I.; Ortega, N. Numerical prediction of heat affected layer in the EDM of aeronautical alloys. Appl. Surf. Sci. 2012, 259, 780-790. [CrossRef]

10. Altin, A.; Nalbant, M.; Taskesen, A. The effects of cutting speed on tool wear and tool life when machining Inconel 718 with ceramic tools. Mater. Des. 2007, 28, 2518-2522. [CrossRef]

11. Thakur, D.G.; Ramamoorthy, B.; Vijayaraghavan, L. Study on the machinability characteristics of superalloy Inconel 718 during high speed turning. Mater. Des. 2009, 30, 1718-1725. [CrossRef]

12. Farhang, B.; Ravichander, B.B.; Venturi, F.; Amerinatanzi, A.; Moghaddam, N.S. Study on variations of microstructure and metallurgical properties in various heat-affected zones of SLM fabricated Nickel-Titanium alloy. Mater. Sci. Eng. A 2020, 774, 138919. [CrossRef]

13. Zhang, D.; Feng, Z.; Wang, C.; Wang, W.; Liu, Z.; Niu, W. Comparison of microstructures and mechanical properties of Inconel 718 alloy processed by selective laser melting and casting. Mater. Sci. Eng. A 2018, 724, 357-367. [CrossRef]

14. Zhang, D.; Niu, W.; Cao, X.; Liu, Z. Effect of standard heat treatment on the microstructure and mechanical properties of selective laser melting manufactured Inconel 718 superalloy. Mater. Sci. Eng. A 2015, 644, 32-40. [CrossRef]

15. Luo, S.; Huang, W.; Yang, H.; Yang, J.; Wang, Z.; Zeng, X. Microstructural evolution and corrosion behaviors of Inconel 718 alloy produced by selective laser melting following different heat treatments. Addit. Manuf. 2019, 30, 100875. [CrossRef]

16. Valdez, M.; Kozuch, C.; Faierson, E.J.; Jasiuk, I. Induced porosity in Super Alloy 718 through the laser additive manufacturing process: Microstructure and mechanical properties. J. Alloys Compd. 2017, 725, 757-764. [CrossRef]

17. Ni, M.; Chen, C.; Wang, X.; Wang, P.; Li, R.; Zhang, X.; Zhou, K. Anisotropic tensile behavior of in situ precipitation strengthened Inconel 718 fabricated by additive manufacturing. Mater. Sci. Eng. A 2017, 701, 344-351. [CrossRef]

18. Qi, H.; Azer, M.; Ritter, A. Studies of standard heat treatment effects on microstructure and mechanical properties of laser net shape manufactured Inconel 718. Metall. Mater. Trans. A 2009, 40, 2410-2422. [CrossRef]

19. Jia, Q.; Gu, D. Selective laser melting additive manufacturing of Inconel 718 superalloy parts: Densification, microstructure and properties. J. Alloys Compd. 2014, 585, 713-721. [CrossRef]

20. Parimi, L.L.; Ravi, G.; Clark, D.; Attallah, M.M. Microstructural and texture development in direct laser fabricated IN718. Mater. Charact. 2014, 89, 102-111. [CrossRef]

21. Ravichander, B.B.; Rahimzadeh, A.; Farhang, B.; Shayesteh Moghaddam, N.; Amerinatanzi, A.; Mehrpouya, M. A Prediction Model for Additive Manufacturing of Inconel 718 Superalloy. Appl. Sci. 2021, 11, 8010. [CrossRef] 
22. Chlebus, E.; Gruber, K.; Kuźnicka, B.; Kurzac, J.; Kurzynowski, T. Effect of heat treatment on the microstructure and mechanical properties of Inconel 718 processed by selective laser melting. Mater. Sci. Eng. A 2015, 639, 647-655. [CrossRef]

23. Tucho, W.M.; Cuvillier, P.; Sjolyst-Kverneland, A.; Hansen, V. Microstructure and hardness studies of Inconel 718 manufactured by selective laser melting before and after solution heat treatment. Mater. Sci. Eng. A 2017, 689, 220-232. [CrossRef]

24. Tillmann, W.; Schaak, C.; Nellesen, J.; Schaper, M.; Aydinöz, M.; Hoyer, K.-P. Hot isostatic pressing of IN718 components manufactured by selective laser melting. Addit. Manuf. 2017, 13, 93-102. [CrossRef]

25. Wang, X.; Keya, T.; Chou, K. Build height effect on the Inconel 718 parts fabricated by selective laser melting. Procedia Manuf. 2016, 5, 1006-1017. [CrossRef]

26. Konečná, R.; Kunz, L.; Nicoletto, G.; Bača, A. Long fatigue crack growth in Inconel 718 produced by selective laser melting. Int. J. Fatigue 2016, 92, 499-506. [CrossRef]

27. Brenne, F.; Taube, A.; Pröbstle, M.; Neumeier, S.; Schwarze, D.; Schaper, M.; Niendorf, T. Microstructural design of Ni-base alloys for high-temperature applications: Impact of heat treatment on microstructure and mechanical properties after selective laser melting. Prog. Addit. Manuf. 2016, 1, 141-151. [CrossRef]

28. Aydinöz, M.; Brenne, F.; Schaper, M.; Schaak, C.; Tillmann, W.; Nellesen, J.; Niendorf, T. On the microstructural and mechanical properties of post-treated additively manufactured Inconel 718 superalloy under quasi-static and cyclic loading. Mater. Sci. Eng. A 2016, 669, 246-258. [CrossRef]

29. Strößner, J.; Terock, M.; Glatzel, U. Mechanical and microstructural investigation of nickel-based superalloy IN718 manufactured by selective laser melting (SLM). Adv. Eng. Mater. 2015, 17, 1099-1105. [CrossRef]

30. Wang, Z.; Guan, K.; Gao, M.; Li, X.; Chen, X.; Zeng, X. The microstructure and mechanical properties of deposited-IN718 by selective laser melting. J. Alloys Compd. 2012, 513, 518-523. [CrossRef]

31. Tian, Y.; Muñiz-Lerma, J.; Brochu, M. Nickel-based superalloy microstructure obtained by pulsed laser powder bed fusion. Mater. Charact. 2017, 131, 306-315. [CrossRef]

32. Konecna, R.; Kunz, L.; Nicoletto, G.; Baca, A. Fatigue crack growth behavior of Inconel 718 produced by selective laser melting. Frat. Ed Integrità Strutt. 2016, 10, 31-40. [CrossRef]

33. Gribbin, S.; Bicknell, J.; Jorgensen, L.; Tsukrov, I.; Knezevic, M. Low cycle fatigue behavior of direct metal laser sintered Inconel alloy 718. Int. J. Fatigue 2016, 93, 156-167. [CrossRef]

34. Lu, Y.; Wu, S.; Gan, Y.; Huang, T.; Yang, C.; Junjie, L.; Lin, J. Study on the microstructure, mechanical property and residual stress of SLM Inconel-718 alloy manufactured by differing island scanning strategy. Opt. Laser Technol. 2015, 75, 197-206. [CrossRef]

35. Amato, K.; Gaytan, S.; Murr, L.E.; Martinez, E.; Shindo, P.; Hernandez, J.; Collins, S.; Medina, F. Microstructures and mechanical behavior of Inconel 718 fabricated by selective laser melting. Acta Mater. 2012, 60, 2229-2239. [CrossRef]

36. Gong, X.; Wang, X.; Cole, V.; Jones, Z.; Cooper, K.; Chou, K. Characterization of microstructure and mechanical property of Inconel 718 from selective laser melting. In Proceedings of the International Manufacturing Science and Engineering Conference, Charlotte, NC, USA, 8-12 June 2015; p. V001T002A061.

37. Popovich, V.; Borisov, E.; Popovich, A.; Sufiiarov, V.S.; Masaylo, D.; Alzina, L. Impact of heat treatment on mechanical behaviour of Inconel 718 processed with tailored microstructure by selective laser melting. Mater. Des. 2017, 131, 12-22. [CrossRef]

38. Elahinia, M.; Shayesteh Moghaddam, N.; Taheri Andani, M.; Amerinatanzi, A.; Bimber, B.A.; Hamilton, R.F. Fabrication of NiTi through additive manufacturing: A review. Prog. Mater. Sci. 2016, 83, 630-663. [CrossRef]

39. Jiang, J.; Xu, X.; Stringer, J. Support structures for additive manufacturing: A review. J. Manuf. Mater. Process. 2018, 2, 64. [CrossRef]

40. Strano, G.; Hao, L.; Everson, R.M.; Evans, K.E. A new approach to the design and optimisation of support structures in additive manufacturing. Int. J. Adv. Manuf. Technol. 2013, 66, 1247-1254. [CrossRef]

41. Hildreth, O.J.; Nassar, A.R.; Chasse, K.R.; Simpson, T.W. Dissolvable Metal Supports for 3D Direct Metal Printing. 3d Print. Addit. Manuf. 2016, 3, 90-97. [CrossRef]

42. Hussein, A.; Hao, L.; Yan, C.; Everson, R.; Young, P. Advanced lattice support structures for metal additive manufacturing. J. Mater. Process. Technol. 2013, 213, 1019-1026. [CrossRef]

43. Vaidya, R.; Anand, S. Optimum Support Structure Generation for Additive Manufacturing Using Unit Cell Structures and Support Removal Constraint. Procedia Manuf. 2016, 5, 1043-1059. [CrossRef]

44. Gan, M.X.; Wong, C.H. Practical support structures for selective laser melting. J. Mater. Process. Technol. 2016, 238 , 474-484. [CrossRef]

45. Calignano, F. Design optimization of supports for overhanging structures in aluminum and titanium alloys by selective laser melting. Mater. Des. 2014, 64, 203-213. [CrossRef]

46. Dias, M.R.; Guedes, J.M.; Flanagan, C.L.; Hollister, S.J.; Fernandes, P.R. Optimization of scaffold design for bone tissue engineering: A computational and experimental study. Med. Eng. Phys. 2014, 36, 448-457. [CrossRef] [PubMed]

47. Hussein, A.; Yan, C.; Everson, R. Preliminary Investigation on Cellular Support Structures Using SLM Process. In Innovative Developments in Virtual and Physical Prototyping; Taylor \& Francis Group: London, UK, 2011.

48. Mishurova, T.; Cabeza, S.; Thiede, T.; Nadammal, N.; Kromm, A.; Klaus, M.; Genzel, C.; Haberland, C.; Bruno, G. The Influence of the Support Structure on Residual Stress and Distortion in SLM Inconel 718 Parts. Metall. Mater. Trans. A 2018, 49, 3038-3046. [CrossRef] 
49. Kajima, Y.; Takaichi, A.; Nakamoto, T.; Kimura, T.; Kittikundecha, N.; Tsutsumi, Y.; Nomura, N.; Kawasaki, A.; Takahashi, H.; Hanawa, T.; et al. Effect of adding support structures for overhanging part on fatigue strength in selective laser melting. J. Mech. Behav. Biomed. Mater. 2018, 78, 1-9. [CrossRef]

50. Chen, H.; Gu, D.; Xiong, J.; Xia, M. Improving additive manufacturing processability of hard-to-process overhanging structure by selective laser melting. J. Mater. Process. Technol. 2017, 250, 99-108. [CrossRef]

51. Liu, Y.; Yang, Y.; Wang, D. A study on the residual stress during selective laser melting (SLM) of metallic powder. Int. J. Adv. Manuf. Technol. 2016, 87, 647-656. [CrossRef]

52. Kruth, J.-P.; Froyen, L.; Van Vaerenbergh, J.; Mercelis, P.; Rombouts, M.; Lauwers, B. Selective laser melting of iron-based powder. J. Mater. Process. Technol. 2004, 149, 616-622. [CrossRef]

53. Pinto, F.; Souza Filho, I.; Sandim, M.; Sandim, H. Defects in parts manufactured by selective laser melting caused by $\delta$-ferrite in reused 316L steel powder feedstock. Addit. Manuf. 2020, 31, 100979. [CrossRef]

54. Pal, S.; Lojen, G.; Kokol, V.; Drstvenšek, I. Reducing porosity at the starting layers above supporting bars of the parts made by Selective Laser Melting. Powder Technol. 2019, 355, 268-277. [CrossRef]

55. Kuo, Y.-H.; Cheng, C.-C.; Lin, Y.-S.; San, C.-H. Support structure design in additive manufacturing based on topology optimization. Struct. Multidiscip. Optim. 2018, 57, 183-195. [CrossRef]

56. Cloots, M.; Spierings, A.; Wegener, K. Assessing new support minimizing strategies for the additive manufacturing technology SLM. In Proceedings of the 24th International SFF Symposium-An Additive Manufacturing Conference, Austin, TX, USA, 16 August 2013; pp. 631-643.

57. Rasband, W.S. ImageJ. National Institutes of Health: Bethesda, Maryland, USA. 2012. Available online: http://imagej.nih.gov/ij/ (accessed on 7 May 2021).

58. Ravichander, B.B.; Amerinatanzi, A.; Shayesteh Moghaddam, N. Study on the Effect of Powder-Bed Fusion Process Parameters on the Quality of as-Built IN718 Parts Using Response Surface Methodology. Metals 2020, 10, 1180. [CrossRef]

59. Ravichander, B.B.; Favela, C.; Amerinatanzi, A.; Shayesteh Moghaddam, N. A Framework for the Optimization of Powder-Bed Fusion Process; SPIE: Long Beach, CA, USA, 2021; Volume 11589.

60. Ravichander, B.B.; Farhang, B.; Swails, N.; Amerinatanzi, A.; Shayesteh Moghaddam, N. Analysis of the deviation in properties of selective laser melted samples fabricated by varying process parameters. In SPIE Smart Structures + Nondestructive Evaluation $\% \mathcal{E}$ SS; SPIE: Anaheim, CA, USA, 2020; Volume 11377.

61. ASTM E92-82: Standard Test Method for Vickers Hardness of Metallic Materials; ASTM International: West Conshohocken, PA, USA, 2003; Volume 82, pp. 1-9.

62. NASA Technical Standards System (NTSS); Specification for Control and Qualification of Laser Powder Bed Fusion Metallurgical Processes. 2017. Available online: https://standards.nasa.gov/standard/msfc/msfc-spec-3717 (accessed on 22 August 2021).

63. Baumers, M.; Dickens, P.; Tuck, C.; Hague, R. The cost of additive manufacturing: Machine productivity, economies of scale and technology-push. Technol. Forecast. Soc. Chang. 2016, 102, 193-201. [CrossRef]

64. Seede, R.; Mostafa, A.; Brailovski, V.; Jahazi, M.; Medraj, M. Microstructural and Microhardness Evolution from Homogenization and Hot Isostatic Pressing on Selective Laser Melted Inconel 718: Structure, Texture, and Phases. J. Manuf. Mater. Process. 2018, 2, 30. [CrossRef]

65. Zhang, F.; Levine, L.E.; Allen, A.J.; Stoudt, M.R.; Lindwall, G.; Lass, E.A.; Williams, M.E.; Idell, Y.; Campbell, C.E. Effect of heat treatment on the microstructural evolution of a nickel-based superalloy additive-manufactured by laser powder bed fusion. Acta Mater. 2018, 152, 200-214. [CrossRef]

66. Levine, L.E.; Geantil, P.; Larson, B.C.; Tischler, J.Z.; Kassner, M.E.; Liu, W. Validating classical line profile analyses using microbeam diffraction from individual dislocation cell walls and cell interiors. J. Appl. Crystallogr. 2012, 45, 157-165. [CrossRef]

67. Levine, L.E.; Larson, B.C.; Yang, W.; Kassner, M.E.; Tischler, J.Z.; Delos-Reyes, M.A.; Fields, R.J.; Liu, W. X-ray microbeam measurements of individual dislocation cell elastic strains in deformed single-crystal copper. Nat. Mater. 2006, 5, 619-622. [CrossRef] [PubMed]

68. Chaturvedi, M.C.; Han, Y.-f. Strengthening mechanisms in Inconel 718 superalloy. Met. Sci. 1983, 17, 145-149. [CrossRef]

69. Mostafa, A.; Picazo Rubio, I.; Brailovski, V.; Jahazi, M.; Medraj, M. Structure, Texture and Phases in 3D Printed IN718 Alloy Subjected to Homogenization and HIP Treatments. Metals 2017, 7, 196. [CrossRef]

70. Pröbstle, M.; Neumeier, S.; Hopfenmüller, J.; Freund, L.P.; Niendorf, T.; Schwarze, D.; Göken, M. Superior creep strength of a nickel-based superalloy produced by selective laser melting. Mater. Sci. Eng. A 2016, 674, 299-307. [CrossRef]

71. Cengel, Y. Heat and Mass Transfer: Fundamentals and Applications; McGraw-Hill Higher Education: New York, NY, USA, 2014.

72. Nickel Alloy, Corrosion and Heat Resistant, Bars, Forgings, and Rings 52.5Ni 19Cr 3.0Mo 5.1Cb 0.90Ti 0.50Al 19Fe, Consumable Electrode or Vacuum Induction Melted $1775^{\circ} \mathrm{F}\left(968^{\circ} \mathrm{C}\right)$ Solution and Precipitation Heat Treated, in AMS5663. Available online: https: / / www.sae.org/standards / content/ams5663 (accessed on 23 July 2021).

73. Nickel Alloy, Corrosion and Heat-Resistant, Investment Castings, 52.5Ni-19Cr-3.0Mo-5.1Cb(Nb)-0.90Ti-0.60Al-18Fe, Vacuum Melted Homogenization and Solution Heat Treated, In AMS5383. Available online: https:/ /www.sae.org/standards/content/ ams5383 (accessed on 21 July 2021).

74. Li, X.; Shi, J.J.; Wang, C.H.; Cao, G.H.; Russell, A.M.; Zhou, Z.J.; Li, C.P.; Chen, G.F. Effect of heat treatment on microstructure evolution of Inconel 718 alloy fabricated by selective laser melting. J. Alloys Compd. 2018, 764, 639-649. [CrossRef] 
75. Cao, G.; Sun, T.; Wang, C.; Li, X.; Liu, M.; Zhang, Z.; Hu, P.; Russell, A.M.; Schneider, R.; Gerthsen, D. Investigations of $\gamma^{\prime}, \gamma^{\prime \prime}$ and $\delta$ precipitates in heat-treated Inconel 718 alloy fabricated by selective laser melting. Mater. Charact. 2018, 136, 398-406. [CrossRef]

76. Ingham, B.; Toney, M.F. 1-X-ray diffraction for characterizing metallic films. In Metallic Films for Electronic, Optical and Magnetic Applications; Barmak, K., Coffey, K., Eds.; Woodhead Publishing: Sawston, UK, 2014; pp. 3-38. [CrossRef]

77. Hakamada, M.; Nakamoto, Y.; Matsumoto, H.; Iwasaki, H.; Chen, Y.; Kusuda, H.; Mabuchi, M. Relationship between hardness and grain size in electrodeposited copper films. Mater. Sci. Eng. A 2007, 457, 120-126. [CrossRef]

78. Van, D.; Dinda, G.P.; Park, J.; Mazumder, J.; Lee, S.H. Enhancing hardness of Inconel 718 deposits using the aging effects of cold metal transfer-based additive manufacturing. Mater. Sci. Eng. A 2020, 776, 139005. [CrossRef]

79. Ronneberg, T.; Davies, C.M.; Hooper, P.A. Revealing relationships between porosity, microstructure and mechanical properties of laser powder bed fusion 316L stainless steel through heat treatment. Mater. Des. 2020, 189, 108481. [CrossRef]

80. Andreau, O.; Koutiri, I.; Peyre, P.; Penot, J.-D.; Saintier, N.; Pessard, E.; De Terris, T.; Dupuy, C.; Baudin, T. Texture control of 316L parts by modulation of the melt pool morphology in selective laser melting. J. Mater. Process. Technol. 2019, 264, 21-31. [CrossRef]

81. Dong, Z.; Liu, Y.; Wen, W.; Ge, J.; Liang, J. Effect of Hatch Spacing on Melt Pool and As-built Quality During Selective Laser Melting of Stainless Steel: Modeling and Experimental Approaches. Materials 2019, 12, 50. [CrossRef] 